\title{
Processing of discourse anaphors by Turkish L2 speakers of English
}

\author{
Derya Çokal \\ School of Electronic Engineering and Computer Science \\ Queen Mary University of London \\ London, E1 4NS, United Kingdom \\ DCOKAL@QMUL.AC.UK
}

Patrick Sturt

Psychology Department, University of Edinburgh

7 George Square Edinburgh,

Midlothian, EH8 9JZ, United Kingdom

Fernanda Ferreira

Psychology Department, University of California, Davis

174A Young Hall 1 Shields Avenue Davis, CA 95616

PATRICK.STURT@ED.AC.UK

FFERREIRA@UCDAVIS.EDU

Editor: Jonathan Ginzburg

Submitted 09/2020; Accepted 07/2021; Published online 08/2021

\begin{abstract}
This study examines the cognitive information processes that Turkish advanced non-native speakers of English employ in assigning the referents of this and that in reading and production. We predicted that these speakers would assign referents in relation to the linear distance between discourse-linked anaphors and their referents in the discourse (i.e., based on spatial-temporal features of this and that), which means they would prefer this for a referent mentioned in the proximal chunk of text and that for a referent mentioned in the distal chunk. We also predicted that readers would not assign referents based on the focusing features of this and that. We tested our predictions in two eyetracking reading experiments and one sentence-completion experiment. Turkish L2 learners' online reference resolution in reading experiments was different from that of English native speakers that were tested in a previous study. In the eye-tracking experiments, Turkish L2 learners did not show evidence of using a recency strategy to resolve referential ambiguity and did not use spatialtemporal or focusing features of this and that to assign referents. On the other hand, in the sentencecompletion experiment, the effect of prominence of discourse structure in the use of this and that was qualitatively similar to that of English native speakers, but their indexing of the degree of focus of this and that was different. Our results suggest that the difference between Turkish L2 learners and English native speakers is due to L1 interference.
\end{abstract}

Keywords: anaphors, processing, demonstratives, non-native speakers, L2 speakers

\section{Introduction}

A language's discursive, pragmatic, and structural features govern speakers' choices of discourse anaphors (d-anaphors) ${ }^{1}$ (e.g., Cornish, 2010;2009; Diessel, 2006). Non-native speakers (L2) use d-

\footnotetext{
${ }^{1}$ Throughout this paper 'discourse anaphors' is shortened to d-anaphors. In spoken discourse, this and that are referred to as demonstratives/deixis, which direct an interlocutor's attention to an entity in a spatial and/or temporal context. In (C)2021 Derya Çokal, Patrick Sturt and Fernanda Ferreira

This is an open-access article distributed under the terms of a Creative Commons Attribution License (http://creativecommons.org/licenses/by/3.0/).
} 
anaphors (e.g., this and that) more extensively than do native speakers (Çokal, 2019; Çokal \& Ruhi, 2006; Ellert, 2013; Ferris, 1994; Hinkel, 2001; Jin, 2001; Juvonen, 1996; Niimura \& Hayashi, 1996; Wilson, Keller, \& Sorace, 2009). In spite of frequent d-anaphor use, L2 speakers demonstrate nontarget patterns in their use of d-anaphors (e.g., Çokal, 2019; Çokal \& Ruhi, 2006; Niimura \& Hayashi, 1996). However, little is known about how L2 speakers select d-anaphors in production, or how they select a referent for this or that in comprehension (Ionin, Baek, Kim, Ko \& Wexler, 2012; Swierzbin, 2010).

Here, we report the results of one sentence-completion experiment and two eye-tracking reading experiments, which are intended to address this gap in the literature. In a previous study, Çokal, Sturt and Ferreira (2014) showed that discourse structure and focus features encoded in danaphors play major roles in native English (L1) speakers' comprehension and production of this and that. The current study is an extension of Çokal et al. (2014), with Turkish L2 speakers of English (EFL). ${ }^{2}$

The aim is to contribute to our understanding of the on-line and offline processing of $\mathrm{d}$ anaphors by Turkish L2 speakers. We examine which factors (spatial-temporal features or degree of focus) affect L2 speakers' biases in establishing the referents of this and that. We also hope to provide an in-depth understanding of the on-line strategy that these speakers use to disambiguate $\mathrm{d}$-anaphors. In the following section, we provide a brief review of semantics and pragmatics of danaphors in English and Turkish, and we discuss evidence about the comprehension strategies employed by native speakers of English, and then offer discussion of what we know about L2 strategies and their relevance to the phenomena we investigate.

\section{Review of Literature}

In this section, we will briefly summarize the previous studies on discourse anaphors.

\subsection{English D-Anaphors in Written Discourse}

This and that bring different elements (e.g., an entity, a proposition, or an event) into focus in written and spoken discourse (Cornish, 2010; Diessel, 2006; Fossard \& Rigelleau, 2005; Levinson, 1993; Linde 1979; McCarthy 1994; Passonneau, 1993; Strauss, 2002). These expressions can be used exophorically (i.e., in reference to entities present in the immediate surroundings of the speech event (Halliday \& Hasan, 1976; Levinson, 1983) or endophorically (i.e., in situations where speakers/writers refer back to elements of the ongoing discourse (Levinson, 1983; Lyons, 1977; see also Peeters, Krahmer, \& Maes, 2020). While exophoric use of this and that has been a main area of research interest for experimental studies, there have been few experimental studies on endophoric use of these expressions in written discourse (Çokal et al., 2014; Peeters, Krahmer, \& Maes, 2020).

In addition, there have been attempts to unify exo- and endo-phoric uses of demonstratives (See Elbourne, 2008; Lücking, 2018; Nunberg, 1993). It is proposed that the difference between endophoric and exophoric demonstratives is the result of finding the referents in two different contexts - utterance situation (i.e., real world) vs. co-text (i.e., written discourse). According to Nunberg's (1993) unified account, it is not the interpretation (i.e., the referent) but the index (i.e., the contextual element and a referred entity) that determines the choice of this and that. For instance, in (1), demonstrations (i.e., pointing gestures) would not be used to identify the referent

addition, we identify this/that as d-anaphors (i.e., deixis in written discourse) since in written discourse they are called 'd-anaphors' or 'anadeixis', which points to a mental representation of a discourse segment in a text (cf. Çokal et al., 2014 for further theoretical discussion).

${ }^{2}$ Throughout this paper, advanced learners of English as a foreign language (EFL) who are native speakers of Turkish are referred to as Turkish non-native speakers of English or as Turkish L2 speakers/learners. 
of that. Instead, a set of entities (e.g., a mask, cape) would be used to anchor or bind that in an utterance.

(1) Melissa made herself a mask and cape; that will be her costume (Nunberg, 1993, p.37).

This is the understanding that has made possible unified accounts of (endophoric) and (exophoric) demonstratives within approaches like Discourse Representation Theory (Lascarides \& Asher, 2007). In this study, we adopt this view and thus specifically focus on endophoric uses of this and that, which direct readers' attention to different parts of a text (Lascarides \& Asher, 2007; McCarthy 1994; Webber, 1991,1989) and update the mental representation of the discourse (Zwaan, 1996).

\subsection{Proximal-distal model vs. focus model}

To account for the functions of this and that in written discourse, the proximal-distal model and the focus model have been proposed.

\subsubsection{Proximal-distal model}

According to McCarthy's (1994) proximal-distal model, this refers to a proximal entity/proposition, whereas that refers to a distal entity/proposition. McCarthy's (1994) proximaldistal model is an extrapolation of the spoken use of demonstratives/deixis. ${ }^{3}$ Unit (a) in (2) below is called the distal frontier (DF), which is separated from this/that by intervening clauses or units. Unit (b), on the proximal frontier (PF), is the intervening clause between the unit with this/that and propositions in units (a) and (c). In (2) and (3), this and that refer to different parts of a text.

(2) This/that referring to a long event on the distal frontier:

(a) Robert ate his meal, annoyed that there was no beer. (b) After he finished eating, he helped his girlfriend to prepare coffee with Scottish whisky and cream. (c) This/That took him 2 hours, and thereafter he was pleased that he had some whisky in his coffee.

(3) This/that referring to a short event on the proximal frontier:

(a) Robert ate his meal, annoyed that there was no beer. (b) After he finished eating, he helped his girlfriend to prepare coffee with Scottish whisky and cream. (c) This/That took him 10 minutes, and thereafter he was pleased that he had some whisky in his coffee.

The difference between item (2) and item (3) is the duration (2 hours vs. 10 minutes) of each event (i.e., having a meal vs. preparing coffee). The suggested interpretation is based on the assumed plausibility that the events take these different amounts of time. According to the proximal-distal model in (2), that is preferred relative to this because the reference is to an event "Robert ate his meal", which is described on the distal frontier (i.e., the non-adjacent portion of text). Thus, that can signal reference across entities or foci of attention (McCarthy, 1994, p. 272). According to the proximal-distal model, in (3) above, this is preferred relative to that, because the reference is to an event described in the immediately preceding adjacent text, namely, "he helped his girlfriend to prepare coffee". The referent of the pronominal this in unit (c) is the event in unit (b) on the PF. The PF is the clause or group of contiguous clauses immediately adjacent to the referential expression and can therefore be regarded as salient/prominent and accessible to referential expressions.

According to the proximal-frontier-only hypothesis, unit (a) on the DF in (2) and (3) is relatively less salient/prominent for referential expressions (Webber, 1989) and thus does not provide referents for this/that. However, an alternative theory, the segmented discourse representation theory (Lascarides \& Asher, 2007) claims that entities on the DF (i.e., unit a) are

\footnotetext{
${ }^{3}$ In a nutshell, 'proximal' demonstratives (e.g., English this) are used in reference to entities relatively nearby the speaker, and 'distal' demonstratives (e.g., English that) in reference to entities relatively far from the speaker (Anderson \& Keenan, 1985; Halliday \& Hasan, 1976; Levelt, 1989).
} 
accessible as long as certain rhetorical relations (e.g., explanation, contrast, or narration between referential expressions and entities/propositions on the DF) are made.

\subsubsection{Focus model}

In contrast to the proximal-distal model, according to Strauss's (2002) focus model, this and that can signal different degrees of focus/attention that the addresser should devote to the referent. Accordingly, this is used to tell an addressee to devote high attention to the referent, since it can also refer to brand new, less salient, or hitherto unshared information. Strauss (2002) contends that in (2) above, this can refer to the event "Robert ate his meal" on the DF. In addition, that is employed to ask an addressee to devote moderate attention to the referent, since it refers to shared and salient information. Therefore, from this perspective, in (3) that can refer to the event "he helped his girlfriend to prepare coffee" on the PF.

However, none of these models was completely supported by empirical findings in a previous study (Çokal et al., 2014), which found that English speakers use a recency strategy and the degree of focus encoded by this and that. We describe this study in detail below, and the current study is an extension of these previous findings.

\subsection{Comprehension strategies by $L 1$ speakers}

Given the longstanding experimental tradition of investigating the cognitive status of different types of anaphors (see Peeters, Krahmer, \& Maes, 2020 for a review on demonstratives) the lack of research into how writers or readers produce or comprehend 'proximal' versus 'distal' demonstrative pronouns is striking. In our previous study, we addressed this gap in the literature and conducted one sentence-completion and two eye-tracking reading experiments to test how L1 speakers of English ${ }^{4}$ resolve the referents of this and that (Çokal et al., 2014).

The first eye-tracking reading experiment compared how this and that refer to distal and proximal events in a context such as the following:

(4) This/that referring to a long event on the distal frontier:

John drove from Edinburgh to Birmingham, listening to his favourite jazz CDs. When he arrived in Birmingham, he filled up the car with petrol. This/That took him 5 hours and afterwards he was happy to have had enough time to go to his hotel to have a rest.

(5) This/that referring to a short event on the proximal frontier:

John drove from Edinburgh to Birmingham, listening to his favourite jazz CDs. When he arrived in Birmingham, he filled up the car with petrol. This/That took him 5 minutes and afterwards he was happy to have had enough time to go to his hotel to have a rest.

Events that took a longer time (e.g., driving from Edinburgh to Birmingham) were given on the distal frontier (i.e., distant segment) as in (4), whereas events that took a shorter time (e.g., filling up the car with petrol) were presented on the proximal frontier (i.e., the segment adjacent to this/that) as in (5). The frontier referent preferences of this and that were measured by referring to matching (e.g., driving from Edinburgh to Birmingham takes 5 hours) or mismatching timespans (e.g., driving from Edinburgh to Birmingham does not take 5 minutes). Native speakers of English showed longer reading times when this and that referred to the event (i.e., driving from Edinburgh to Birmingham) on the DF (as in 4) than when referring to the event on the PF (as in 5).

To replicate the results of Experiment 1, in the second eye-tracking experiment (see Method in Experiment 2.), Çokal et al. (2014) changed the order of events: events of shorter duration (e.g., he filled up the car with petrol) were moved to the DF, while events of longer duration (e.g., John drove from Edinburgh to Birmingham) were placed on the PF. As in Experiment 1, regardless of

\footnotetext{
${ }^{4}$ In this study, the native speakers of English did not speak other languages and were living in Scotland Native speakers of non-British varieties of English (e.g., North American or Australian) were not recruited.
} 
whether this or that was used, references to the event on the PF led to shorter L1 reading times (e.g., indicative of preference) than references to the event on the DF. This suggests that native speakers of English do not use the proximal-distal model (i.e., this can refer to a proximal/recent entity/proposition, whereas that refers to a distal entity/proposition (cf. McCarthy's proximal-distal model, 1994). In addition, they did not employ 'degrees of attention' encoded by this and that (cf. Strauss' focus account, 2002). In addition, the on-line reading experiments demonstrated that native speakers of English preferred both this and that to refer to the event on the proximal frontier. However, references to the distal frontier with this and that led to processing difficulties.

In the sentence-completion experiment, they used the same stimuli, but with a blank after the words following this/that in each sentence:

John drove from Edinburgh to Birmingham, listening to his favourite jazz CDs. When he arrived in Birmingham, he filled up the car with petrol. This/That

When completing the sentence, English writers' references to propositions/events on the PF (with both this and that) were more frequent than DF references. However, this was more likely than that to refer to the DF. In accordance with Strauss's (2002) focus account, the findings suggest that references with this signal the English writer is asking the interlocutor to place a high focus on the referent, since the referent is 'less salient' and related to the 'earlier part of discourse'. On the other hand, with that, the English writer is asking the interlocutor to place a medium focus on the referent, since the referent is on the PF, and thus is providing information on the adjacent frontier.

In summary, Çokal et al. (2014) showed that when L1 English speakers are reading, they use a recency strategy and prefer references to salient propositions or events on the PF (i.e., prominent unit in discourse), rather than references to less salient propositions or events on the DF (i.e., less salient/prominent). Their findings of a 'recency strategy' to resolve a referential ambiguity support previous psycholinguistic studies (e.g., Anderson, Garrod, \& Sanford, 1983; Ehrlich \& Rayner, 1983; Klin, Guzman, Weingartner, \& Ralano, 2006; O’Brien, Raney, Albrecht, \& Rayner, 1997). Again, in sentence completion, English writers mostly refer to salient propositions on the PF. However, when L1 English speakers refer to less salient propositions on the DF, they prefer this to that, which suggests their preferences are governed by: (1) the prominence of discourse frontiers (i.e., distal/less salient vs. proximal/salient) and (2) the degree of focus an addressee must devote in order to resolve ambiguity (i.e., high vs. medium focus). Having discussed Çokal et al.'s (2014) findings from L1 speakers, we will now briefly describe Turkish d-anaphors.

\subsection{Turkish D-Anaphors}

In Turkish, the use of referential expressions (overt or null) is determined by the discourse context, and conveys pragmatic information such as contrast, similarity, emphasis or new information (Enç, 1986; Erguvanl1-Taylan, 1986). Once the discourse topic is set with a noun phrase or overt pronoun, continuity requires the use of null pronouns. But when the speaker wants to mark a topic change, an overt pronoun is necessary for grammaticality (Öztürk, 2001). In the cases of d-anaphors in Turkish, an overt pronoun is used.

While a threefold d-anaphora system $(b u, s u$, and $o$ ) is commonly seen in spoken discourse (Kornfilt, 1997; Küntay \& Özyürek, 2006; Lyons, 1977), a twofold anaphoric system, using bu/this and o/that, is generally observed in written discourse (Sağın-Şimşek, Rehbein, \& Babur, 2009; Turan, 1997). Since şu is used cataphorically and the current paper's focus is on the anaphoric uses of this and that, we will not mention the functions of şu below.

It should be noted that Turan's (1997) investigation of written discourse, in which she examined the cognitive status of $b u$ in the establishment of attentional structure, revealed that to signal topic continuation, $b u$ refers to an entity on the PF. Similarly, Özil and Şenöz (1996) 
proposed that $b u$ can be used anaphorically to refer to propositions, clauses or verb-phrases (VPs) as antecedents.

Sağın-Şimşek et al. (2009) made implicit analogies between d-anaphors in written discourse and those in spoken discourse. They investigated the use of $b u$ and $o$ in two novels (Babamin Bavulu by Orhan Pamuk and Mavi Karanlik by Vedat Turkali) and annotated their references to an entity/proposition. While $b u(n=89)$ refers to an entity that is in the focus of reader/listener (i.e., an entity on the proximal frontier), $o(n=59)$ refers to an entity that is distal to the focus of reader/listener (i.e., an entity on the distal frontier). $O$ is used to refocus an entity that is mentioned earlier in the text. The use of Turkish d-anaphors in written discourse is determined by the linear distance between d-anaphors and their referents in discourse (i.e., spatial-temporal features of $b u$ and $o$ ).

Having reviewed findings on Turkish d-anaphors, in the next section we briefly summarize how non-native speakers (L2) of English process and produce this and that in written discourse.

\subsection{Comprehension strategies by $L 2$ speakers}

The question of whether L2 and L1 sentence processing are similar has long been debated (e.g., Clahsen \& Felser, 2006). Within the domain of anaphora processing, theories of L2 acquisition (Sorace, 2011) have been informed by the question of whether L2 speakers can acquire native-like interpretive preferences for demonstratives/personal pronouns (e.g., Ellert, 2013; Niimura \& Hayashi, 1996; Wilson et al., 2009), and whether L2 preferences vary between task types (Roberts, Gullberg, \& Indefrey, 2008). Wilson et al. (2009) and Ellert (2013) both investigated demonstratives in German, However, Wilson et al. (2009) examined their uses in the context of animate references, while Ellert (2013) explored their uses in inanimate references. So, though the type of demonstratives they tested cannot refer to events or propositions such as this/that in English, below we briefly summarize their findings under two categories ([1] on-line studies showing L2 on-line processing deficits and [2] L1 interferences), in order to make inferences based on the similarity of the phenomena under investigation in the current study.

\subsubsection{L2 on-line studies}

In visual world paradigm experiments ${ }^{5}$ involving a judgment task, Wilson et al. (2009) examined whether English-speaking learners of German used grammatical role (Subject-VerbObject [SVO] order vs. Object-Verb-Subject [OVS] order) or thematic role (Active vs. Passive conditions with SVO and OVS word order) in assigning referents of referential expressions (personal pronouns [er, sie, es] vs. demonstrative pronouns [der, die, das]). ${ }^{6}$ In German, while er is often used to refer to the first mentioned entity (e.g., entity in subject position), der is used to index a topic shift (i.e., focus change from the first mentioned entity to the less salient entity (e.g., focus change from entity in subject position to an entity in object position). To examine this, Wilson et al (2009) used the sentences like (6) and tested whether participants prefered er referring to firstmentioned noun phrase (NP1) references (i.e., Der Kellner) and der referring to second-mentioned noun phrase (NP2) references (i.e., detektiv).

(6) Der Kellner erkennt den Detektiv, als das Bier umgekippt wird.

Er/Der ist offensichtlich sehr fleißig.

The waiter recognises the detective as the beer is tipped over.

\footnotetext{
5 The visual-world paradigm (in which participants listen to a sentence or short text while their eye-movements are recorded as they look at a scene or series of images) exploits the fact that the interpretation of auditory linguistic input influences eye-movements for scenes or images (see Altmann \& Kamide, 2007).

${ }^{6}$ Wilson et al. (2009) reported three experimental strands on (1) information structure and pronominalization, (2) antecedent preferences of anaphoric demonstratives/ pronouns, and (3) simulating L2 learners' difficulties in native speakers. Here we only report the most relevant experiment to our current study.
} 


\section{$\mathrm{He} / \mathrm{Der}$ is clearly very hard working.}

Wilson et al. (2009) showed that German native speakers (L1) had different referent preferences for different types of referential expressions: personal pronouns (i.e., er) for NP1 references and demonstratives (e.g., der) for NP2 references. While L1 and L2 speakers of German interpreted personal pronouns similarly, English-speaking learners of German (L2) did not consistently interpret demonstratives as 'indexing a topic-shift'. In addition, they 'had no clear preference for NP2s' as antecedents of demonstratives. Overall, L2 speakers preferred both personal pronouns and demonstratives for NP1 references. They also preferred first-mentioned entity/topic references, irrespective of type of referential expressions (i.e., er or der) or information structure (i.e., for the salient NP/first-mentioned NP vs. less salient NP2).

In the light of these findings, Wilson et al. (2009) proposed that L2 learners might have difficulty efficiently integrating different sources of information in on-line processing and thus have a deficit in 'resource allocation' during on-line processing. To link correct antecedents and referential expressions, L2 learners need to integrate many sources of information: (a) the current discourse model (i.e., which entities have been mentioned and are prominent), (b) real world knowledge, (c) syntactic knowledge (i.e., er is used for topic references whereas der can shift attention from NP1 to NP2).

Similarly, using a visual-world eye-tracking paradigm and an offline referent assignment task, Ellert (2013) tested the preferences Dutch learners of German for personal pronouns (e.g., German er) with topical references (i.e., references to an entity in subject position) as in (7a), and demonstratives (e.g., German der) with non-topical references (i.e., references to an entity in object position as in (7b).

(7a) Der Schrank ist schwerer als der Tisch. Er (personal pronoun condition) stammt aus einem Möbelgeschäft in Belgien. Das Sofa soll nächste Woche geliefert werden.

(7b) Der Schrank ist schwerer als der Tisch. Der (d-pronoun condition)

stammt aus einem Möbelgeschäft in Belgien. Das Sofa soll nächste Woche geliefert warden.

'The cupboard is heavier than the table. It (personal/demonstratives) originates from a furniture store in Belgium. The sofa is supposed to be delivered next week.'

(Ellert, 2013, p. 178)

Similar to Wilson et al.'s (2009) findings, Dutch-speaking learners of German had a topic-reference preference (i.e., NP1) for pronouns/demonstratives. However, they did not have distinct referent preferences for different types of anaphora, even though Dutch and German have similar pronoun/demonstrative systems. Ellert (2013) proposed that the L2 on-line processing cannot be merely explained by L1 influences but needs to take more general L2 learner effects into account. ${ }^{7}$

These two studies indicate that L2 learners develop a 'learner specific' referent assignment strategy involving a first mentioned-entity/topic-reference preference irrespective of anaphora types (Ellert, 2013; Wilson et al., 2009). These findings also suggest that observed non-target uses of L2 speakers in interpreting d-anaphors cannot simply be explained by L1 influence (Ellert, 2013), since irrespective of L2 speakers' native language (i.e., typologically similar or different anaphora system), they exhibited non-target antecedent preferences for demonstratives.

\footnotetext{
${ }^{7}$ Unmarked referential expressions signal that their referent is a continuation of the topic previously established. On the other hand, marked referential expressions direct the reader to new entities or topics that are not highly salient. Therefore, for L2 learners the referential expression "that" can bring a less salient entity into focus and signal an addressee to raise high focus (i.e., attention calling).
} 


\subsubsection{L1 interference}

In a sentence completion experiment that examined typologically different anaphora systems across different languages (i.e., English/non-null language vs. Japanese/null language) with English L1 native speakers and Japanese L2 learners of English, English L1 speakers assigned the referents of demonstratives based upon focus encoded in demonstratives, whereas Japanese L2 speakers' demonstrative choice was based on the entity's spatial-temporal distance (Niimura \& Hayashi, 1996). For instance, one of the illustrated cartoon characters notices a stain on the carpet, bends down to have a closer look and says, "Hmm, a bad stain on the carpet'. His face is close to the stain and thus this is not an instance of proximity. In this case, $68 \%$ of L1 speakers chose that, while $28 \%$ chose this \& $3 \%$ chose it, while non-native (L2) speakers preferred this $69 \%$ of the time, that $18 \%$, and it $13 \%$.

In an accompanying illustration, a character finds a piece of paper on the floor while he is standing upright, looking down at a piece of paper. He utters, "Hello? What's...?". In this situation, $76 \%$ of the L1 speakers chose this over that (24\%), even though the character's physical distance from the referent is greater. On the other hand, 55\% of L2 speakers preferred this, while 44\% preferred that, and only $1 \%$ chose $i t$. It should be noted, that in both instances, L2 speakers preferred this over that. Niimura and Hayashi (1996) state that in an identical context in Japanese, the appropriate response for L1 speakers would be ko/this because both cases fall in the domain of a speaker's direct experience and anything within the speaker's territory, especially something within reach, is referred to by $k o$. While native speakers of English chose demonstratives on the basis of focus (Strauss, 2002) instead of the physical proximity of the referent, Japanese L2 learners' preference was based on physical distance to the referent.

In another study, L2 learners' performance changed across on-line and offline tasks (Roberts, Gullberg, \& Indefrey, 2008). In an acceptability judgement task, while Dutch L1 speakers and German L2 speakers of Dutch both interpreted an overt pronoun as referring to a discourse topic, Turkish-speaking L2 speakers of Dutch chose an overt pronoun as indexing a topic shift. This shift brings a new entity into the discourse, since Turkish is a null subject language, and an overt pronoun is used to change topics. Consequently, the offline preference of Turkish L2 speakers of Dutch was for an overt pronoun to index a topic shift, which was evidence of language transfer from Turkish to Dutch. However, in on-line reading tasks this L1 interference was not seen; both Turkish and German L2 learners had processing disadvantages irrespective of the anaphora systems in their native language.

In addition, in an on-line eye-tracking experiment, Roberts et al. (2008), tested how both German and Turkish L2 learners of Dutch read sentences with/without competitor antecedents in the preceding discourse for personal pronouns. Both German and Turkish L2 groups had similar preferences, which were different from Dutch native speakers. Specifically, when reading the critical region (i.e., the verb and subject: eet hij "he eats"), their second pass and total reading times were longer in a condition in which there were two grammatically matching referents available (Peter and Hans are in the office. While Peter is working, he is eating a sandwich.), then in a condition with only one grammatically available referent (The workers are in the office. While Peter is working, he is eating a sandwich.). Based upon their experiment results, Roberts et al. (2008) propose that during real-time comprehension, L2 learners find the integration of information from multiple sources more difficult than do native speakers, since they need to coordinate syntactic and semantic or pragmatic information.

In summary, previous L2 on-line studies demonstrate: (1) L2 learners may not 'index topicshift' with demonstratives, resulting in unclear or inconsistent referent preferences of demonstratives (Ellert, 2013; Wilson et al., 2009), and (2) their non-target use might not be due to L1 interference (Ellert, 2013). Instead, such non-target use may be related to a deficit in 'resource allocation' (Wilson et al., 2009) or difficulties integrating information from multiple resources during on-line processing (Roberts et al., 2008). While previous offline studies point to L1 interference (Niimura and Hayashi, 1996), Roberts et al. (2008) found L1 interference in offline 
tasks, but there was no evidence of L1 interference in on-line tasks. However, there were L2 processing disadvantage - irrespective of native language - in on-line tasks.

When we examine L2 studies, we see that so far they have involved comparisons between personal pronouns and demonstratives but not examinations within d-anaphors. However, they have not assessed whether L2 learners index the focusing features of this and that, or how L2 learners identify the referents of this and that in either comprehension or sentence production. In addition, to our knowledge, we still do not know what on-line strategies Turkish-speaking L2 learners use when disambiguating d-anaphors. Importantly, the studies discussed above have mostly focused on English, German, Dutch, and Italian L2 speakers but not Turkish L2 speakers. Thus, the current study will provide results on the development of discourse-conditioned structures for Turkish learners of English. More importantly, unlike English, Turkish is a null-subject language. Therefore, when there is a topic continuation between (8a) and (8b), referents are maintained with a null pronoun (as in $8 b$ ). In (8a) and (8b), the narrator explains what $\mathrm{s} /$ he did yesterday. In (8c), a new character 'Murat' is introduced. In (8d), the overt pronoun $o$ is used to state that the narrator did like the movie, but Murat did not. It should be noted that in Turkish, overt pronouns are used when the referent is marked for contrast or topic shift (cf. Enc, 1986).

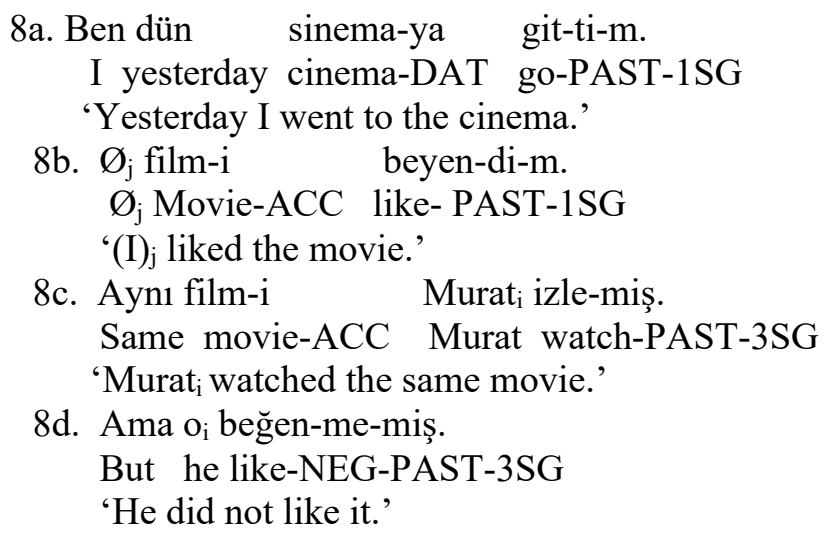

The use of d-anaphors in Turkish is a special case, in which addressers use them overtly. In both English and Turkish, information structure (i.e., salience of DF and PF) plays a role in the use of d-anaphors.

In most language-teaching textbooks used in Turkey for students to learn English, only the spatial-temporal aspects of English d-anaphors are explicitly highlighted, and the degree of focus encoded by d-anaphors is not taught (Cokal, 2019). From an educational perspective, the role of instruction on L2 development of d-anaphors is important, since the degree of focus of this and that is perceptually less salient/subtle and might go unnoticed for L2 learners (cf. DeKeysar, 2002; reviews of the experimental and quasi-experimental investigations into the effectiveness of L2 instruction in Ellis, 2015; Ellis, 2008). Specifically, in an EFL context, Turkish L2 learners are often not exposed to naturally occurring input. Consequently, the efficient use of this and that requires Turkish L2 learners/writers to learn the similarities and differences across these two languages.

While the effect of instruction on L2 development is not the current focus of the study, it is still important background information, worthy of examination. With this in mind, in the next section, we will list the current study's hypotheses.

\subsection{The current study}

Given previously obtained results (Çokal et al., 2014), in this study the following account is assumed for native English speakers: L1 English speakers consider (a) 'the prominence of discourse structure' and thus prefer an event on the PF as a referent of this and that, and also (b) the degree 
of focus an addressee needs to devote to a less salient/distal event on the DF and thus prefer this to that. Based on what is currently known in Niimura and Hayashi (1996), we predicted that Turkish L2 speakers of English would not index the 'degree of focus' encoded by this and that and thus they would not use this to refer to a less salient event on the DF. Instead, they would use the spatialtemporal features encoded by this and that. They would prefer this when referring to a salient/proximal event on the PF (i.e., an event on the clause adjacent to this) and that when referring to a less salient/distal event on the DF (i.e., an event on the distal clause to that).

The L2 speakers' non target pattern may be due to L1 interference. Basically, Turkish L2 learners would transfer what they know about this and that to their on-line processing and offline production. In written discourse, $b u$ - corresponds to this (i.e., refers to an entity/event that has been mentioned recently in the text), whereas $o$ - corresponds to that (i.e., refers to an earlier entity/event in the text) (Sağın-Şimşek, Rehbein, \& Babur, 2009). In addition, in spoken discourse, both $o$ (i.e., referring to distal elements) and şu (e.g., pure attention calling) are mapped onto that. Therefore, unlike native speakers of English, for Turkish L2 learners, that but not this can refer to an event on the DF (Çokal, 2020; Çokal \& Ruhi, 2006).

Alternatively, Turkish L2 learners would not consider either 'degree of focus' or 'spatialtemporal features' of this and that. They would only consider 'prominence of discourse structure' and thus would use recency strategy (i.e., both this and that referring to an event given on the PF).

Turkish L2 learners' referent preferences were observed to change across offline and online tasks (Roberts et al., 2008). With such findings in mind, we predicted that Turkish L2 learners' referent choices might be much clearer in an offline task (i.e., sentence completion) than an on-line task. On the other hand, in an on-line task (i.e., on-line reading experiment), they would not use 'spatial-temporal features' of this and that, degree of focus, or recency strategy to disambiguate this/that. If so, then our results would suggest that these L2 learners have disadvantages in on-line processing. To disambiguate the referents of this/that, they need to do the following: (a) maintain 'global coherence' and keep track of what information is accessible, (b) follow information structure to determine salient/accessible or less salient/less accessible events on the discourse frontiers, (c) match these frontiers with degree of focus encoded by this and that, (d) avoid L1 interference (i.e., spatial-temporal features of $b u$ and $o$ ), and (e) use real world knowledge about event structures. This process requires them to handle d-anaphora systems in two languages and distinguish 'form-functions of d-anaphors' in both English and Turkish. Thus, if they do not have referent preferences for this and that, then based on the previous findings (Roberts et al., 2008; Wilson et al., 2009), we could propose that in on-line reading, they would have a processing deficit in the integration of all this information.

To test our predictions, we conducted three experiments: one offline sentence-completion study and two on-line eye-tracking experiments. While the on-line experiments were conducted first, for presentational purposes we will report the offline experiment (Experiment 1) first and then the two on-line experiments. In Experiment 1, we examined Turkish L2 preferences during the use of this and that in narrative completions. In Experiments 2 and 3, in order to observe Turkish L2 speakers' processing of this and that in narrative written discourse, we recorded eye-movements during reading.

\subsubsection{Participants}

Participants in three experiments were Turkish L2 speakers of English who were third or fourthyear students in the Foreign Language Teaching Department at Middle East Technical University (METU). All volunteers were between 21 and 24 years of age $(\mathrm{M}=22 ; \mathrm{SD}=1.126)$, unaware of the study's purpose, paid for their participation, and had not spent extended periods of time in English-speaking countries. However, all participants had passed METU's mandatory first-year English proficiency exam, which includes listening and writing tests. Participants' mean proficiency exam score was $81(\mathrm{SD}=3.39)$, which is equal to 102 TOEFL (IBT) or 7.5 IELTS (See conversion table http://oidb.metu.edu.tr/en/english-proficiency). The METU mean proficiency 
score supports categorizing participants as L2 advanced speakers (for a conversion table with levels of proficiency in English, see http://www.eurogates.nl/en-TOEFL-IELTS-score-conversion/). In addition, it should be noted that the medium of instruction at METU is English; therefore, students are required to speak and write in English in all courses.

\section{Experiment 1}

Experiment 1 tested Turkish L2 preferences using a sentence completion method. Although this technique does not provide any insight into the time-course of processing, experience in our laboratory has shown it to be a very sensitive measure of reference assignment preferences, which is presumably because it is less vulnerable to individual differences (i.e., the timing with which information is used in processing), compared with an on-line method such as eye-tracking.

\subsection{Method}

In this section, we will describe our participants, materials, and data analysis.

\subsubsection{Participants}

Participants were paid Turkish advanced non-native speakers of English $(n=30)$. The L2 participants in this sentence-completion experiment were a subset of those of Experiments $2 \& 3$. The sentence completion experiment was conducted eight months after Experiment 3. Once again, participants were not informed of the study's purpose and had not spent time in English speaking countries.

\subsubsection{Materials}

We used the same stimuli as in Experiment 2 below. Differently from Experiment 2, each participant was provided with an initial sentence/context and the remainder of the second sentence (after this or that) was left blank. In an initial context, we always gave a long event (e.g., driving from Istanbul to Zonguldak) on the distal frontier of discourse and a short event (e.g., filling up the car with petrol) on the proximal frontier. The initial context always included a sequence of events. Therefore, the DF and PF were in narration relation. We indicated the end of the long event using when or after adverbial clause.

Each participant was asked to provide a completion answer for the sentence in a manner consistent with the previous text. A sample stimulus is given below:

Berk drove from Istanbul to Zonguldak, listening to his favourite jazz CDs. When he arrived in Zonguldak, he filled up the car with petrol. This

There were 40 experimental and 60 filler sentences (See Item 4 in Appendix.). There were two experimental conditions, one of which included the word this as the final word before the blank (as in the sample above), and the other of which included the word that. Two versions of each sentence and two files were constructed, using Latin Square counterbalancing. In each file, each sentence appeared in only one condition, with an equal number of items from each condition. Sentences were presented on the computer in a fixed random order.

\subsubsection{Procedures}

At the beginning of each trial, participants looked at a blank square on the monitor to generate a new stimulus, and then completed the sentence given in the stimulus by speaking aloud in a clear voice.

\subsubsection{Data Analysis}


Though our purpose was to investigate Turkish L2 speakers' pronominal use of this and that, we also coded their uses of this and that as prenominals (this/that + Noun Phrase [NP]). When coding prenominal uses, we also considered whether the L2 speakers referred to proposition/events on the distal or proximal frontiers (e.g., This/that + NP referring to an entity on DF or PF).

We used the following continuation codings and samples for prenominal and pronominal this and that.

- If pre(pro)nominal this or that referred to the short event, then its referent was coded as the proximal frontier referent:

(1) Ozlem went to the hairdresser, hoping to get the latest hairstyle. When she was at the hairdresser, she looked through the magazines for inspiration. This made her confused about the new hairstyles.

(2) Aysun watched her favorite TV show Heroes, relaxing on her sofa. After she had watched the final episode, she prepared a face mask with a little milk and avocado. That mask helped her get rid of all the spots on her face.

- If pre(pro)nominal this or that referred to the distal clause with the long event, then its referent was coded as the early clause referent:

(1) Derya had face-to-face meetings with her clients, highlighting the new product features. Before she left her office, she visited the ladies' room downstairs. That was very tiring. (2) Mary went to the hairdresser, hoping to get the latest hairstyle. When she was at the hairdresser, she looked through the magazines for inspiration. This hairdresser was the one she has been going to for the last 10 years.

- If prenominal this or that referred to a group of sentences, then the group of sentences was entered as referent.

(1) Faruk planted 50 roses, following all the instructions. After he had planted the roses with great care, he watered them with a watering can. That was an exciting experience for him and he was looking forward to seeing them grow.

(2) Murat washed his Peugeot 407, listening to Capital FM. After he had cleaned the outside of his car, he vacuumed the floor, including the area beneath the seats. This was a preparation for the wedding of one of his friends.

- Other categories: if the referents of this or that were not clear, if the new discourse focus was introduced by the use of this or that, if this or that was used with time expressions such as this night or that evening, or if incoherent sentences were made with the previous part of the text, then all these cases were coded as other categories.

Two PhD students (unaware of the purposes of the experiment) independently transcribed the data and coded the continuations according to the categories given to them. There was high interrater reliability on the referents of this and that (Cohen's kappa: this: $>0.85$; that $>0.81$; this $\mathrm{NP}>0.89$; that $\mathrm{NP}<0.85$ ). Twenty continuations that annotators did not understand were excluded from data analysis.

\subsection{Results}

Figure 1 shows the relative proportions of references to the DFs and PFs, as a function of danaphors type in Turkish L2's completions. Figure 2 highlights the distribution of other types of references. Because data for this experiment are categorical, the statistical analyses in this section used logistic mixed effects regression, taking condition (this vs. that) as the fixed effects, and 
including crossed random intercepts and slopes for participants and items: response $\sim$ (condition $+1 \mid$ subject $)+($ condition $+1 \mid$ item $)+$ condition. Data and scripts are available at http://osf.io/v2msd/

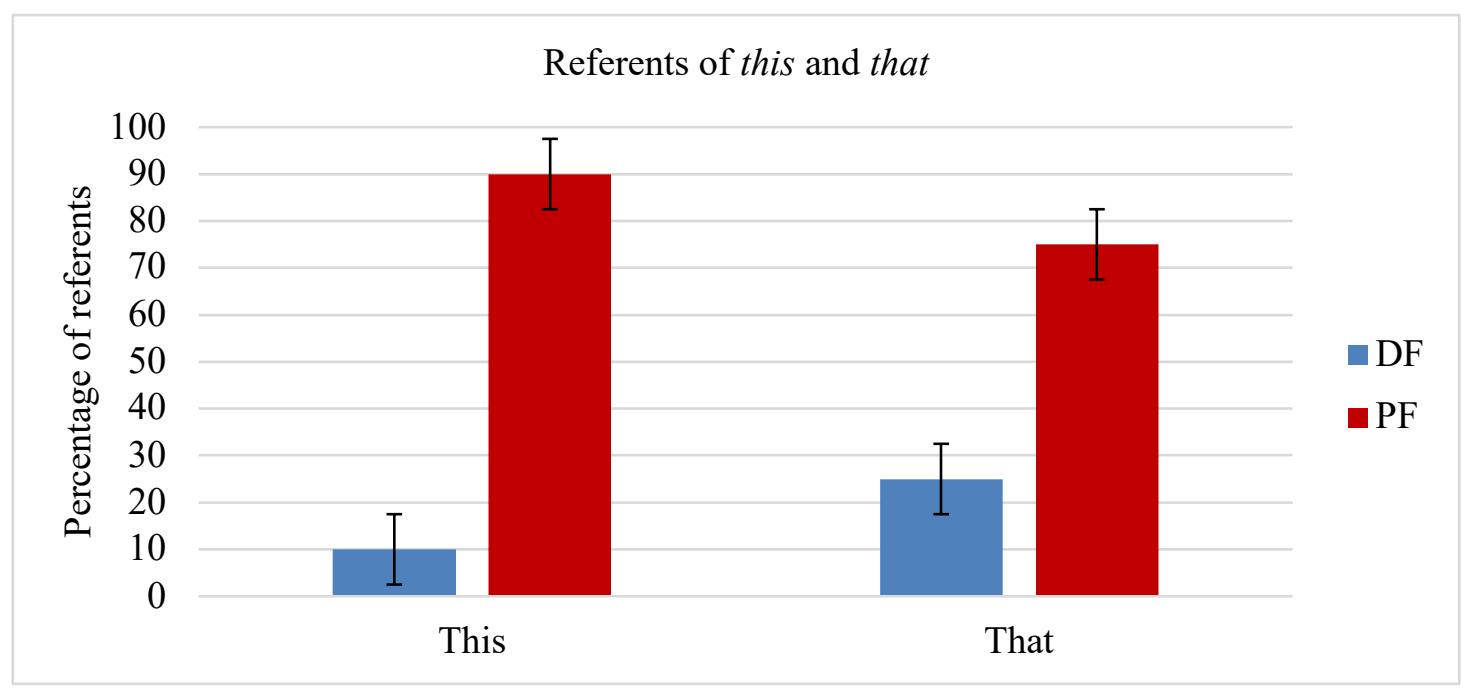

Figure 1. Turkish L2 speakers' choice of referents of this and that (i.e., pronominals). Error bars show standard errors.

In $27 \%$ of cases, this and that were used prenominally (e.g., this trip) or their antecedents were unclear (Please see Appendix Item A1.). The proportion of these trials (coded as other) did not differ between this and that conditions $(Z=-0.392, p=.70)$. These prenominal cases were analysed separately from the pronominal usages, since the prenominal and pronominal usages are linguistically and cognitively distinct (See the differences in Ariel, 1996; Gundel, Hedberg, \& Zacharski, 1993.).

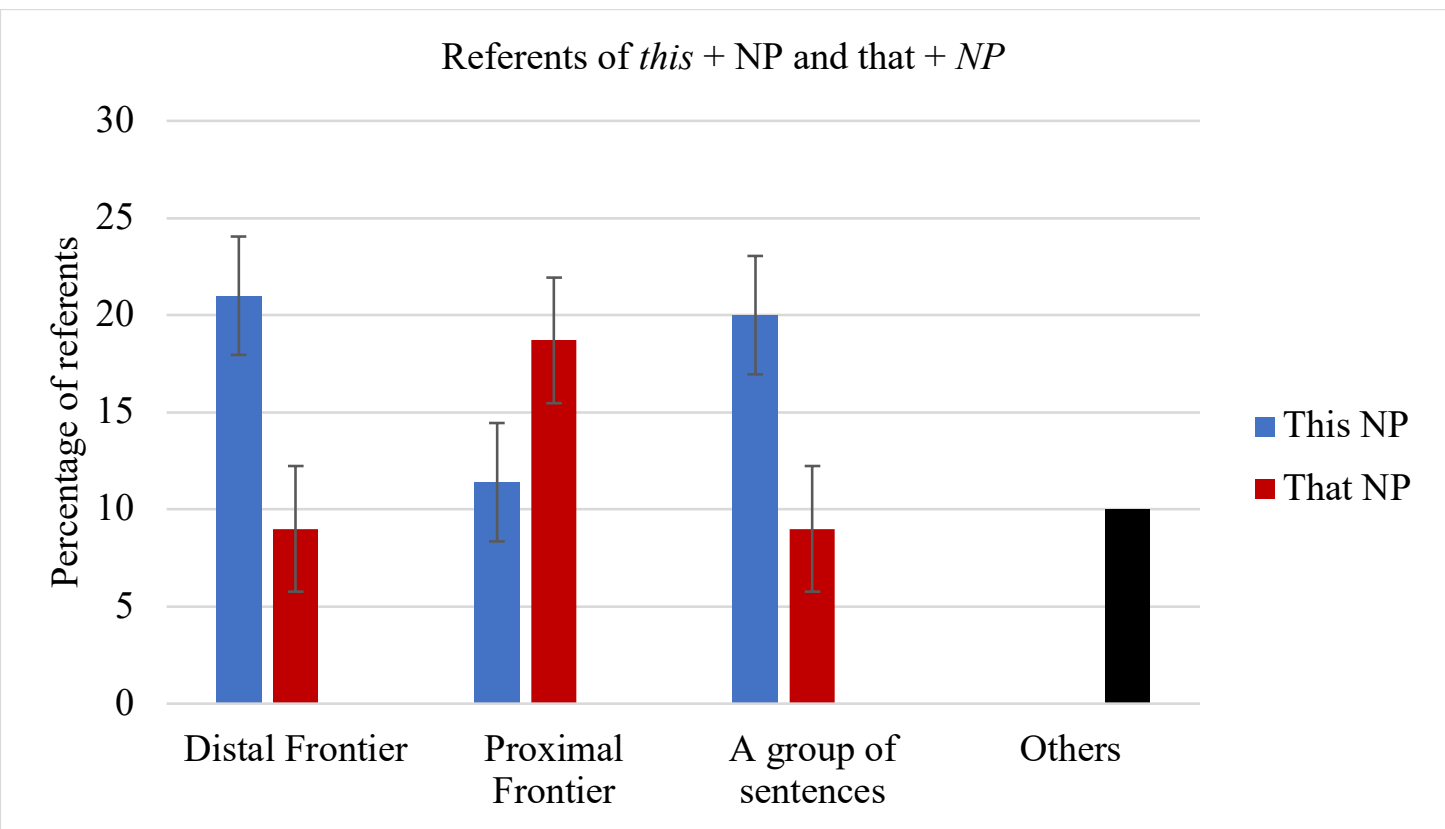

Figure 2. Turkish L2 speakers' percentages of other categories. Error bars show standard errors.

In this and that conditions, the Turkish L2 speakers had a strong preference for the PF reference (This $=90.1 \%$, That $=75.29)$. In the logistic mixed effects regression, we coded references to the 
$\mathrm{DF}$ as 0 and the $\mathrm{PF}$ as 1 . The intercept was significantly different from zero $(\hat{\beta}=1.55, \mathrm{Z}=5.187$, $\mathrm{p}<.001$, reflecting the overall preference for the PF reference (See Appendix Item A1.). The logistic mixed effect analysis revealed a main effect of condition $(\hat{\beta}=1.20, \mathrm{Z}=5.79, \mathrm{p}<.001)$. The Turkish L2 learners referred to the PF more with this than with that (this $\mathrm{PF}=90 \%$; that $\mathrm{PF}=75 \%$ ). Correspondingly, the complementary pattern for reference to the DF was this DF $=10 \%$ and that $\mathrm{DF}=25 \%$.

The Turkish L2 speakers used this +NP more frequently than that+NP when referring to the events on the DF (DF: this $+\mathrm{NP}=21 \%$; that $+\mathrm{NP}=9 \%$ ) (Figure 2) (See Appendix Item A1.). References to the events on the PF were more frequent with that $+\mathrm{NP}$ than this $+\mathrm{NP}(P F:$ this $+\mathrm{NP}$ $=38 \%$, that $+\mathrm{NP}=62 \%$ ). For the L2 speakers, this $+\mathrm{NP}$ can more easily access the events on the DF than that $+\mathrm{NP}$. Thus, the frequency of references with that $+\mathrm{NP}$ to the events on the PF was higher than with this $+\mathrm{NP}$. For Turkish L2 learners, pronominal that is more deictically marked ${ }^{8}$ than this and therefore it can more easily refer to events on the DF, relative to this. This $+\mathrm{NP}$ is more deictically marked than that $+\mathrm{NP}$ and thus can access propositions on the DF.

\subsection{Conclusion}

In summary, in the sentence-completion experiment, like English native speakers (Çokal et al., 2014), Turkish L2 speakers predominantly used this and that to refer to propositions on the PF of the discourse structure. In addition, they had the following biases: this for the event on the PF and that for the event on the DF. In the prenominal cases, the Turkish L2 speakers preferred this $+\mathrm{NP}$ over that $+\mathrm{NP}$ to refer to an event on the DF. In this experiment, the difference between English native speakers and Turkish L2 learners was indexing 'the degree of focus' encoded by this and that. Therefore, L1-speaker referent preferences are opposite to those of L2 speakers: this for references to less salient/less accessible proposition on the DF and that for salient/shared and focused elements on the PF.

The results show that Turkish L2 speakers are able to use this and that differentially to refer to different parts of texts and bring different elements into focus. The sentence-completion experiment showed that Turkish L2 speakers' uses of this and that are governed by L1 interference, with $b u$ (corresponding to this) used for references to salient/proximal/focused elements and $o$ (corresponding to that) used for references to less salient/distal/unfocused elements. It is worth emphasizing that the large correspondence between L1 and L2 was the result of the PF being strongly preferred.

\section{Experiment 2}

Experiment 2 was an eye-tracking in reading study using Turkish L2 speakers, and it was based closely on Experiment 1A of Çokal et al.'s (2014), which used L1 speakers of English. The experiment had a $2 \times 2$ within-subjects design, crossing two levels of deictic expressions (this and that) with two levels of discourse frontiers (proximal and distal) as seen in Example 9 below:

(9a) This referring to a long event on the distal frontier of discourse:

Berk drove from Istanbul to Zonguldak, listening to his favourite jazz CDs. When he arrived in Zonguldak, he filled up the car with petrol. This took him 5 hours, and afterwards he was happy to have had enough time to go to his hotel to have a rest.

(9b) That referring to a long event on the distal frontier of discourse

\footnotetext{
${ }^{8}$ Unmarked referential expressions signal that their referent is a continuation of the topic previously established. On the other hand, marked referential expressions direct the reader to new entities or topics that are not highly salient. Therefore, for our L2 learners the referential expression "that" can bring a less salient entity into focus and signal an addressee to raise high focus (i.e., attention calling).
} 
Berk drove from Istanbul to Zonguldak, listening to his favourite jazz CDs. When he arrived in Zonguldak, he filled up the car with petrol. That took him 5 hours, and afterwards he was happy to have had enough time to go to his hotel to have a rest.

(9c) This referring to a short event on the proximal frontier of discourse

Berk drove from Istanbul to Zonguldak, listening to his favourite jazz CDs. When he arrived in Zonguldak, he filled up the car with petrol. This took him 5 minutes, and afterwards he was happy to have had enough time to go to his hotel to have a rest.

(9d) That referring to a short event on the proximal frontier of discourse

Berk drove from Istanbul to Zonguldak, listening to his favourite jazz CDs. When he arrived in Zonguldak, he filled up the car with petrol. That took him 5 minutes, and afterwards he was happy to have had enough time to go to his hotel to have a rest.

The events on the proximal and distal frontiers, which served as referents for this and that, differed in their typical time duration (see 9a, 9b, 9c, and 9d). As in (9a, 9b), the DF described an event of relatively "long" duration (i.e., driving from Istanbul to Zonguldak), while as in (9c, 9d), the PF described an event of relatively "short" duration that was part of the "long" event (i.e., filling up the car with petrol). In the critical sentence, this and that referred to a specific event that was of either long (e.g., five hours) or short (e.g., five minutes) duration, matching either the long event on the DF or the short event on the PF. After this and that, in order to present the time duration that the long and short events required, we used the same structure ... took him/her + time duration throughout the stimuli. After the time duration, the second clause started with and, followed by adverbials with seven or more characters (e.g., and afterwards) to allow for the possibility participants would see some of that word parafoveally while fixating on and. All long event clauses had a modifier (e.g., listening to his favourite Jazz CDs). In order to prevent modifiers being mistaken for a referent of this and that, attention was paid to not introduce a new event or use psychological verbs (e.g., planning or thinking). In order to signal that two different events were being mentioned and to indicate the end of the long event and the start of a new one, adverbial clauses with after, once or when were provided before clauses with short events (e.g., When he arrived in Zonguldak). In addition, the long event was always on the DF (the distal clause in the first sentence), while the short event was always on the PF (the immediately preceding clause in the second sentence).

We conducted this time duration manipulation since we assumed that reference assignment to an event occurs soon after a subject reads the d-anaphor at the start of the critical sentence. In addition, we surmised that Turkish L2 learners should exhibit processing difficulty if the length of the event (e.g., driving from Istanbul to Zonguldak) did not match the time duration subsequently mentioned in the critical sentence (e.g., five minutes). Thus, differences in reading times among conditions should indicate which event was initially chosen as the referent.

\subsection{Predictions}

Here, we assumed that if Turkish L2 learners would have any unclear or indeterminate referential preferences for this and that, then there would be no reading time differences in $(9 \mathrm{a}, 9 \mathrm{~b}$, 9c, and 9d). Alternatively, we assumed that if L2 speakers relied on spatial-temporal functions of this and that (e.g., references to the distal/proximal frontiers), then processing difficulty should be greater and reading times would be longer when this referred to the event on the distal frontier (as in 9a) and that referred to the event on the proximal frontier (as in 9d). This interaction should be observed at the disambiguating region where L2 readers first encounter the disambiguating information, which will be reflected in regression path at the disambiguation region. If L2 readers refixate on the d-anaphors region after disambiguation, then the interaction will be found in the $d$ anaphors region in second pass reading time and total time, since these measures include refixations after the reader has progressed beyond the analysis region. 
Another possibility was that the reverse pattern for this and that would be observed if readers were sensitive to the degree of focus encoded by this and that. Consequently, reading times would be longer when this referred to the event on the PF (as in 9c) and that referred to the event on the DF (as in 9b). This preference will be seen in regression path time for the disambiguating region and in second pass and total time for the d-anaphors region. In addition, if the DF was inaccessible, then reading times for both this and that should be generally longer for references to the DF (as in 9a, 9b) than the PF (as in 9c, 9d).

\subsection{Method}

In this section, we will describe our participants, materials, and data analysis.

\subsubsection{Participants}

Participants were Turkish L2 speakers of English $(n=52)$.

\subsubsection{Materials}

There were 40 experimental items, in each of the four experimental conditions illustrated ( $9 \mathrm{a}$, 9b, 9c, and 9d) (See Item 5 in Appendix.). In the four constructed files, each sentence appeared in only one condition and each condition appeared an equal number of times. There were 60 fillers and eight practice items, all of which were similar in length to the control sentences. In the filler items, events involved causes and consequences. Texts were presented on 3-4 written lines of between 66 to 76 characters. This and that always appeared in the second sentence around the middle of the line. Each participant saw all the fillers.

\subsubsection{Procedures}

We presented 108 texts in a fixed random order, so no two experimental items appeared adjacent to each other. Thirteen participants were assigned to each list. In order to familiarize participants with the experimental procedure, the experiment began with eight fillers. The experiment was conducted using an Eyelink 1000 eye-tracker (SR Research Ltd, Ottawa, Canada) in tower-mounted mode, with a chin rest to stabilize the participant's head. Items appeared on a monitor approximately $80 \mathrm{~cm}$ from the participant's eyes. Only the right eye was tracked, but viewing was binocular. Before each item, participants fixated on a black square so the experimenter could check calibration of subject's eyes. After reading each item, participants pressed the X-button on the controller to see the corresponding comprehension question, the left button for the answer option on the left [False], and the right button for the option on the right [True]. The comprehension questions never probed the referents of this/that (e.g., Did Berk drive to Kastamonu?). We asked participants to read the sentences at a natural pace, and then answer the question accurately and, if possible, quickly.

\subsubsection{Data analysis}

Individual fixations of less than $80 \mathrm{~ms}$ and more than $1200 \mathrm{~ms}$ were excluded from the analysis. Such long fixations usually indicate tracker loss. All the participants scored at least $90 \%$ correct on their answers to the questions, and the analyses below include all trials regardless of question-answering accuracy. We did not exclude participants/trials because the by-participant intercepts adjust for individual differences in reading speed, and the log transformation in our model reduces the impact of individual trials with extreme values. Texts were divided into three regions (see Table 1), and we report analyses for regions 1, 2, and 3. 


\begin{tabular}{ll}
\hline Analysis Region & \\
\hline R1 D-anaphor & This/that took him \\
R2 Time duration & 5 hours $/ 5$ minutes \\
R3 Connector and adverbial & , and afterwards \\
\hline
\end{tabular}

Table 1. Analysis Regions (R) in Experiment 2

All analyses were conducted using linear mixed effects regression (LMER) and the lme4 R package. ${ }^{9}$ An additional package (plyr) was used to compute p-values. For each region and measure, an LMER model, incorporating all fixed effects and their interactions in a single step, was constructed (Barr et al., 2013). Factor labels were transformed into numerical values and centered prior to analysis, to have a mean of 0 and a range of 1 . The results provide coefficients, standard errors, and t-values for each fixed effect and interaction. Analysis was based on log reading times, and all analyses reported below incorporated crossed random intercepts for participants and items. Random slope parameters (levels of deictic expressions) (e.g., this and that), two levels of frontiers (e.g., proximal and distal), and the interaction in the slopes (danaphors* frontiers +1 |participants) were included in the maximal model for both participants and items (see Table 2). Data and scripts are available at http://osf.io/v2msd

Regression path times were defined as the sum of all fixations from the first entry into the region from the left until the first fixation to a later region and were our measure of early processing (reflecting the fixation behaviour that immediately follows the reader's initial inspection of a given region). In the analysis of regression path times, trials where the reader skipped the region of interest during initial reading were removed from the analysis and treated as missing data. The second pass reading measure was defined as the sum of all fixation durations following the first exit of the region either to the right or left, and it therefore excluded time spent during the initial reading of a region. Therefore, this gives information about delayed aspects of processing, as well as the re-processing required when a reader looks back at a portion of text. For second pass reading times, if a region was not re-fixated, this would result in a value of zero for the relevant trial. Such trials values (i.e., those with no re-fixations) were removed from the second pass reading analysis. Total reading times were the sum of all fixations in the region, reflecting overall processing. For total reading time, regions with no fixations in any given trial were treated as missing data and removed from total reading time analysis.

\subsection{Results}

Regression path times did not reveal a significant interaction between d-anaphor and discourse frontier, or any main effects of discourse frontier (See Tables $2 \& 3$ and Figure 3.)

\footnotetext{
${ }^{9}$ R 3.6.0 GUI 1.70 El Capitan build (7657).
} 


\begin{tabular}{|c|c|c|c|c|c|c|c|c|c|}
\hline \multirow{3}{*}{$\begin{array}{l}\text { Regions \& } \\
\text { Parameters } \\
\text { R1: D-anaphors }\end{array}$} & \multicolumn{9}{|c|}{ Eye-movement measures } \\
\hline & \multicolumn{3}{|c|}{ Regression path times } & \multicolumn{3}{|c|}{ Second reading times } & \multicolumn{3}{|c|}{ Total reading times } \\
\hline & $\widehat{\widehat{\beta}}$ & $\mathrm{SE}$ & $\mathrm{t}$ & $\widehat{\beta}$ & $\mathrm{SE}$ & $\mathrm{t}$ & $\widehat{\beta}$ & SE & $\mathrm{t}$ \\
\hline Intercept & 6.38 & 0.04 & 142 & 5.39 & 0.02 & 268 & 6.50 & 0.05 & 130 \\
\hline D-anaphors & -0.01 & 0.02 & -0.48 & 0.02 & 0.32 & 0.81 & -0.06 & 0.02 & $-* 2.52$ \\
\hline Frontiers & -0.03 & 0.03 & -1.14 & -0.06 & 0.27 & $-* 2.04$ & -0.04 & 0.02 & -1.869 \\
\hline $\begin{array}{l}\text { D-anaphors x } \\
\text { Frontiers } \\
\text { R2: Time } \\
\text { duration }\end{array}$ & -0.00 & 0.05 & -0.11 & 0.00 & 0.05 & -0.15 & 0.01 & 0.05 & 0.198 \\
\hline Intercept & 5.73 & 0.04 & 141 & 5.36 & 0.01 & 275 & 5.83 & 0.04 & 136 \\
\hline D-anaphors & -0.00 & 0.02 & -0.22 & -0.04 & 0.03 & -1.60 & -0.00 & 0.02 & -0.03 \\
\hline Frontiers & -0.06 & 0.03 & -1.77 & 0.00 & 0.03 & 0.07 & -0.03 & 0.02 & -1.41 \\
\hline $\begin{array}{l}\text { D-anaphors x } \\
\text { Frontiers } \\
\text { R3: Connector } \\
\text { \& adverbial }\end{array}$ & 0.03 & 0.05 & 0.53 & 0.01 & 0.06 & 0.17 & 0.01 & 0.05 & 0.191 \\
\hline Intercept & 6.02 & 0.03 & 156 & 5.35 & 0.02 & 238 & 6.11 & 0.04 & 138 \\
\hline D-anaphors & -0.01 & 0.02 & -0.68 & 0.00 & 0.03 & 0.15 & -0.02 & 0.02 & -1.17 \\
\hline Frontiers & 0.00 & 0.03 & 0.03 & -0.01 & 0.04 & -0.32 & -0.03 & 0.02 & -1.33 \\
\hline $\begin{array}{l}\text { D-anaphors x } \\
\text { Frontiers }\end{array}$ & 0.01 & 0.06 & 0.20 & -0.08 & 0.07 & -1.09 & -0.01 & 0.05 & -0.22 \\
\hline
\end{tabular}

*Statistically significant effects are indicated with asterisk. Effects are considered significant when the absolute value of $t$ was 2 or greater.

Table 2. Experiment 2: Results of mixed-effects analysis for the eye-movement measures (complex model) 


\begin{tabular}{llll}
\hline Regions & Regression path & Second pass & Total reading \\
\hline $\begin{array}{l}\text { R1: D-anaphors } \\
\text { This DF }\end{array}$ & $813(58)$ & $240(9)$ & $790(35)$ \\
That DF & $750(38)$ & $235(9)$ & $837(37)$ \\
This PF & $749(53)$ & $221(6)$ & $752(32)$ \\
That PF & $718(39)$ & $217(8)$ & $785(33)$ \\
R2: Time duration & & & \\
This DF & $421(34)$ & $213(6)$ & $420(15)$ \\
That DF & $474(56)$ & $228(9)$ & $425(18)$ \\
This PF & $378(22)$ & $223(8)$ & $408(18)$ \\
That PF & $427(40)$ & $226(11)$ & $420(24)$ \\
R3: Connector \& & & & \\
adverbial & & & \\
This DF & $484(25)$ & $228(8)$ & $541(23)$ \\
That DF & $555(56)$ & $222(11)$ & $556(28)$ \\
This PF & $544(42)$ & $208(7)$ & $511(20)$ \\
That PF & $519(39)$ & $222(6)$ & $524(23)$ \\
\hline
\end{tabular}

Table 3. Experiment 2: Means (and standard errors) for regression-path times, second pass reading times and total reading times.

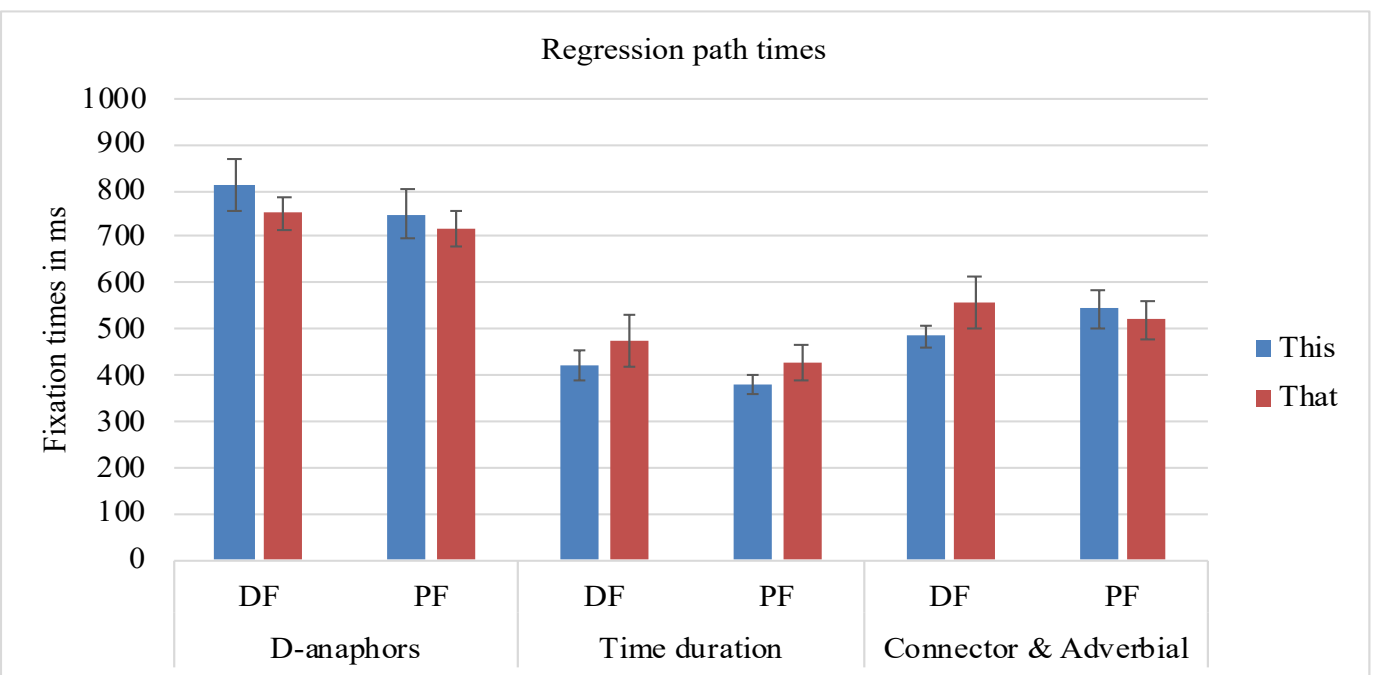

Figure 3. Regression path times (ms) across regions, for Experiment 2. Error bars show standard errors.

In second pass reading times (See Appendix Item A2.), for the region of d-anaphors (R1), a main effect of discourse frontier was found (See Tables $2 \& 3$ and Figure 4). Second pass reading times were longer when this/that referred to the long event on the distal frontier than those with the proximal frontier (DF: $\mathrm{M}=237, \mathrm{SE}=9.67$; $\mathrm{PF}: \mathrm{M}=219, \mathrm{SE}=7.27$ ). 


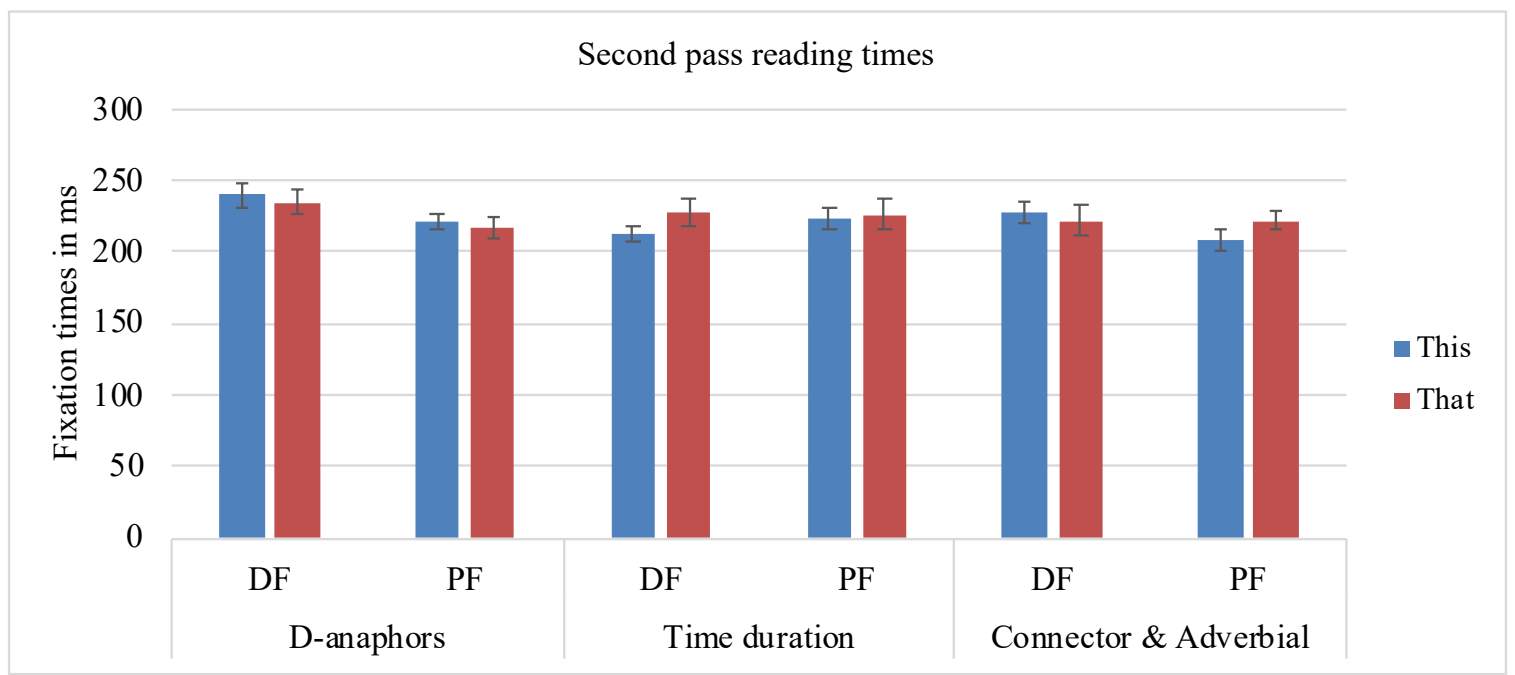

Figure 4. Second pass reading times (ms) across regions, for Experiment 2. Error bars show standard errors.

In total reading times (See Appendix Item A2.), for the region of d-anaphors (R1), a main effect of d-anaphor was found (see Tables $2 \& 3$ and Figure 5). Total reading times were longer when that was used than when this was used (that: $\mathrm{M}=811, \mathrm{SE}=24.73$; this: $\mathrm{M}=771, \mathrm{SE}=23.71$ ).

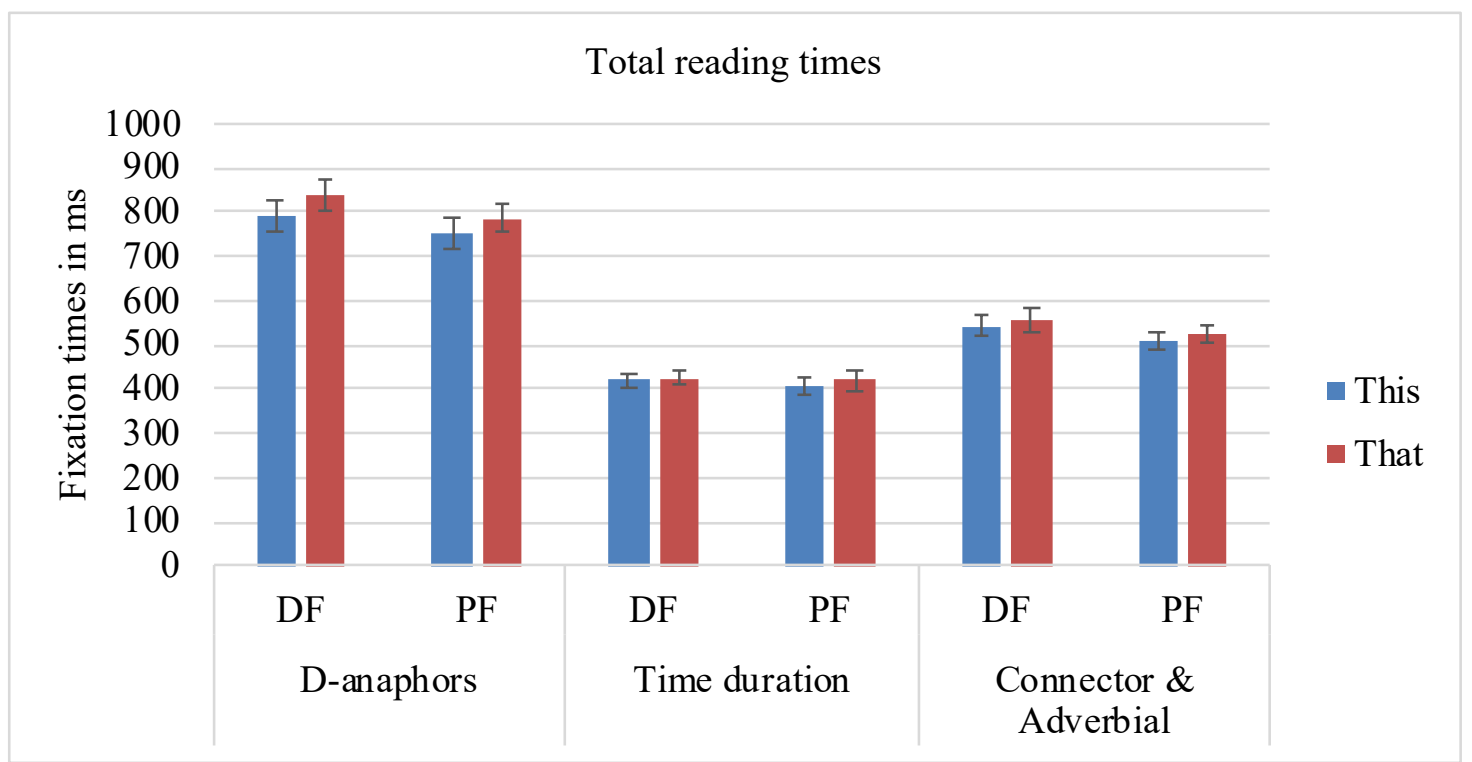

Figure 5. Total reading times (ms) across regions, for Experiment 2. Error bars show standard errors.

\subsection{Conclusion}

The results of Experiment 1 show some evidence consistent with the claim that, similarly to native English speakers in Çokal et al. (2014), Turkish L2 speakers of English preferred references to the proximal frontier, regardless of whether this or that was used. However, Turkish L2 learners' preferences for PF references were only seen in second pass reading times and in only the d-anaphor region. Reading times for Turkish L2 learners were longer when this and that referred to the event on the DF. Experiment 2 results do not show evidence that Turkish L2 learners' preferences involved 'spatial-temporal' or 'degree of focus' features of this and that. 


\section{Experiment 3}

In Experiment 3, we investigated whether Turkish L2 speakers of English would have different referent preferences for this and that if the order of the long and short events in the context was changed. Experiment 3 (using L2 speakers of English) was an extension of Çokal et al. (2014) and designed to rule out a potential alternative interpretation of Experiment 2's results, which had suggested faster reading times for references to the short event on the PF, relative to references to the long event on the DF. We interpreted Experiment 2's results as a mismatch effect, showing a preference for proximal-frontier reference for both this and that. However, the results could also be interpreted as demonstrating a reading preference for short time durations (e.g., five minutes) relative to long durations (e.g., five hours) or a referent preference for short events over long ones. If so, this might be unrelated to the referent's distal or proximal-frontier status.

\subsection{Method}

In this section, we will describe our participants, materials, and data analysis.

\subsubsection{Participants}

Turkish L2 participants in Experiment $3(n=40)$ had taken part in Experiments 1 and 2. However, experiments 2 and 3 were conducted at least six months apart. During this ensuing timeperiod, participants did not spend an extended period of time in English-speaking countries.

\subsubsection{Materials}

To rule out this potential counter-explanation, we replicated Experiment 2's design, changing only the order of events (i.e., The "short" event was moved to the DF and the "long" event was moved to the PF.), as seen in Example 10 below:

(10a) This referring to a long event on the proximal frontier:

Berke filled up the car with petrol, being careful not to spill any over his white wedding trousers. Then he drove from Istanbul to Zonguldak. This took him 5 hours, and afterwards he was happy not to have had to stop on his way.

(10b) That referring to a long event on the proximal frontier:

Berke filled up the car with petrol, being careful not to spill any over his white wedding trousers. Then he drove from Istanbul to Zonguldak. That took him 5 hours, and afterwards he was happy not to have had to stop on his way.

(10c) This referring to a short event on the distal frontier:

Berke filled up the car with petrol, being careful not to spill any over his white wedding trousers. Then he drove from Istanbul to Zonguldak. This took him 5 minutes, and afterwards he was happy not to have stained his trousers.

(10d) That referring to a short event on the distal frontier:

Berke filled up the car with petrol, being careful not to spill any over his white wedding trousers. Then he drove from Istanbul to Zonguldak. That took him 5 minutes, and afterwards he was happy not to have stained his trousers.

Another difference from Experiment 2, was that the end of the "short" event and the start of the "long" event was indicated by an adverbial (e.g., then), instead of an adverbial clause (e.g., when or after) in Experiment 3 (See Item 6 in Appendix.). 


\subsubsection{Predictions}

If Turkish L2 speakers showed a preference for reference to the PF as in Experiment 2, then we should again observe faster reading times for references to the event on the PF in (10a, 10b) even though this event now involved a "long" duration, relative to the "short" event depicted in the clause on the DF in (10c, 10d). However, if Turkish L2 speakers merely took less time to process "short" durations than "long" durations, then the opposite pattern should be found. Again, L2 preferences would be revealed in regression path at the disambiguation region and in second pass reading time and total time at the d-anaphors region. L2 preference in regression path at the danaphors region is not interpretable since they have not yet encountered disambiguating information.

\subsubsection{Procedures}

The procedure was the same as Experiment 2.

\subsubsection{Data analysis}

All details of data analysis were identical to those of Experiment 2.

\section{$5.2 \quad$ Results}

All participants correctly answered at least $90 \%$ of the comprehension questions. There were no comprehension differences across conditions in either Experiment 2 or Experiment 3. All trials are included in the analyses. The results of regression path times, second pass reading time, and total reading times (See Appendix Item A3.) of L2 speakers of English are reported in Tables 4 and 5 .

Eye-movement measures

\begin{tabular}{|c|c|c|c|c|c|c|c|c|c|}
\hline \multirow{2}{*}{$\begin{array}{l}\text { Regions \& } \\
\text { Parameters } \\
\text { R1:D-anaphors }\end{array}$} & \multicolumn{3}{|c|}{ Regression path times } & \multicolumn{3}{|c|}{$\begin{array}{l}\text { Second pass reading } \\
\text { times }\end{array}$} & \multicolumn{3}{|c|}{ Total reading times } \\
\hline & $\widehat{\beta}$ & $\mathrm{SE}$ & $\mathrm{t}$ & $\widehat{\beta}$ & SE & $\mathrm{t}$ & $\widehat{\beta}$ & $\mathrm{SE}$ & $\mathrm{t}$ \\
\hline Intercept & 6.35 & 0.04 & 130 & 6.03 & 0.04 & 132 & 6.40 & 0.05 & 123 \\
\hline D-anaphors & -0.02 & 0.02 & -0.80 & 0.00 & 0.06 & 0.05 & 0.00 & 0.02 & 0.28 \\
\hline Frontiers & 0.06 & 0.03 & 1.87 & 0.04 & 0.06 & 0.75 & 0.02 & 0.02 & 1.04 \\
\hline $\begin{array}{l}\text { D-anaphors x } \\
\text { Frontiers }\end{array}$ & 0.06 & 0.06 & 0.96 & 0.09 & 0.12 & 0.75 & -0.04 & 0.05 & -0.86 \\
\hline $\begin{array}{l}\text { R2: Time } \\
\text { duration }\end{array}$ & & & & & & & & & \\
\hline Intercept & 5.65 & 0.03 & 154 & 6.01 & 0.05 & 112 & 5.73 & 0.05 & 113 \\
\hline D-anaphors & -0.07 & 0.03 & $*-2.26$ & -0.02 & 0.08 & -0.23 & -0.01 & 0.02 & -0.59 \\
\hline
\end{tabular}


ÇOKAL, STURT AND FERREIRA

$\begin{array}{lccccccccc}\text { Frontiers } & 0.01 & 0.03 & 0.49 & 0.03 & 0.08 & 0.42 & -0.03 & 0.03 & -1.11 \\ \begin{array}{l}\text { D-anaphors x } \\ \text { Frontiers }\end{array} & -0.00 & 0.07 & -0.01 & -0.13 & 0.16 & -0.81 & 0.01 & 0.06 & 0.29 \\ & & & & & & & & & \end{array}$

\section{R3: Connector \\ \& adverbial}

$\begin{array}{lccccccccc}\text { Intercept } & 5.94 & 0.04 & 133 & 6.08 & 0.05 & 111 & 6.05 & 0.04 & 133 \\ \text { D-anaphors } & 0.00 & 0.01 & 0.20 & 0.05 & 0.10 & 0.52 & -0.01 & 0.02 & -0.60 \\ \text { Frontiers } & --- & --- & ---- & 0.01 & 0.10 & 0.12 & -0.04 & 0.02 & -1.70 \\ & & & & & & & & & \\ \text { D-anaphors x } & 0.01 & 0.01 & 0.93 & -0.00 & 0.23 & -0.00 & -0.00 & 0.05 & -0.01\end{array}$

Frontiers

*Statistically significant effects are indicated with asterisk. Effects are considered significant when the absolute value of $t$ was 2 or greater.

Table 4. Experiment 3: Results of mixed-effects analysis for the eye-movement measures (complex model)

\begin{tabular}{llll}
\hline Regions & Regression path & Second pass & Total reading \\
\hline $\begin{array}{l}\text { R1: D-anaphors } \\
\text { This DF }\end{array}$ & $648(31)$ & $528(47)$ & $700(35)$ \\
That DF & $783(64)$ & $531(39)$ & $687(44)$ \\
This PF & $719(43)$ & $601(51)$ & $704(39)$ \\
That PF & $761(57)$ & $646(90)$ & $722(38)$ \\
R2: Time duration & & & \\
This DF & $343(26)$ & $546(58)$ & $371(25)$ \\
That DF & $379(27)$ & $574(61)$ & $394(28)$ \\
This PF & $337(20)$ & $702(126)$ & $365(22)$ \\
That PF & $473(64)$ & $633(93)$ & $380(22)$ \\
R3: Connector \& adverbial & & & \\
This DF & $440(25)$ & $615(111)$ & $499(31)$ \\
That DF & $476(30)$ & $591(74)$ & $510(29)$ \\
This PF & $467(27)$ & $612(80)$ & $479(24)$ \\
That PF & $540(103)$ & $699(196)$ & $490(24)$ \\
\hline
\end{tabular}

Table 5. Experiment 3: Means (and standard errors) for regression-path times, second pass reading times and total reading times. 


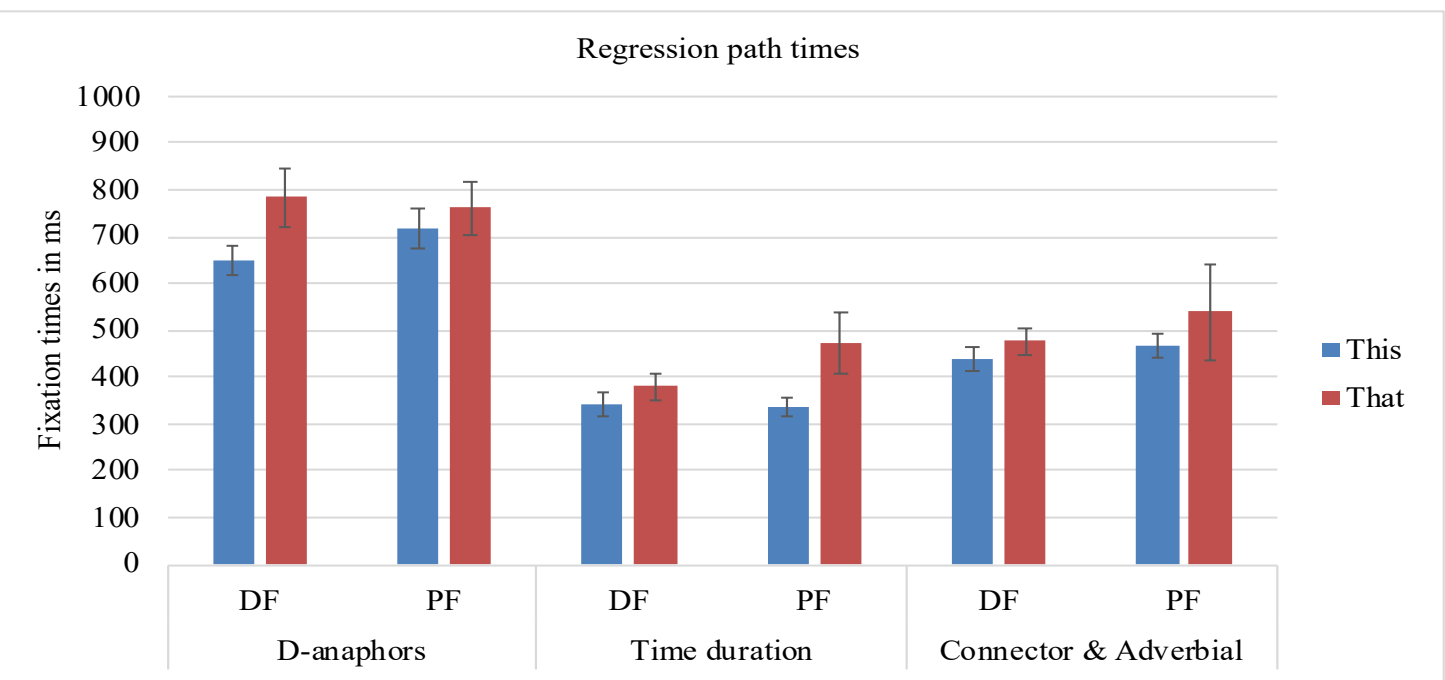

Figure 6. Regression path times (ms) across regions, for Experiment 3. Error bars show standard errors.

In regression path times, for the d-anaphors region (R1), there were no main effects or interaction. A pairwise comparison showed that this referring to the DF was significantly different from that referring to the DF $(\mathrm{t}=-2.108, \mathrm{p}=.036)$ (See Tables $4 \& 5$, Figure 6.). However, this result is uninterpretable and superfluous because it was not replicated in other regions or eyemovement measures. In addition, it was seen before participants encountered the disambiguating region. In regression path times, for the time duration region (R2), there was a main effect of danaphors (see Tables $4 \& 5$ and Figure 6). References to the events with that led to longer regression path times than references to the events with this (that: $\mathrm{M}=426, \mathrm{SE}=35.73$; this: $\mathrm{M}=$ $339, \mathrm{SE}=16.20)$. No main effect or interaction was seen in other regions $(\mathrm{R} 1, \mathrm{R} 3)$ for regression path, second pass reading, and total reading times (see Tables $4 \& 5$ and Figures $7 \& 8$ ).

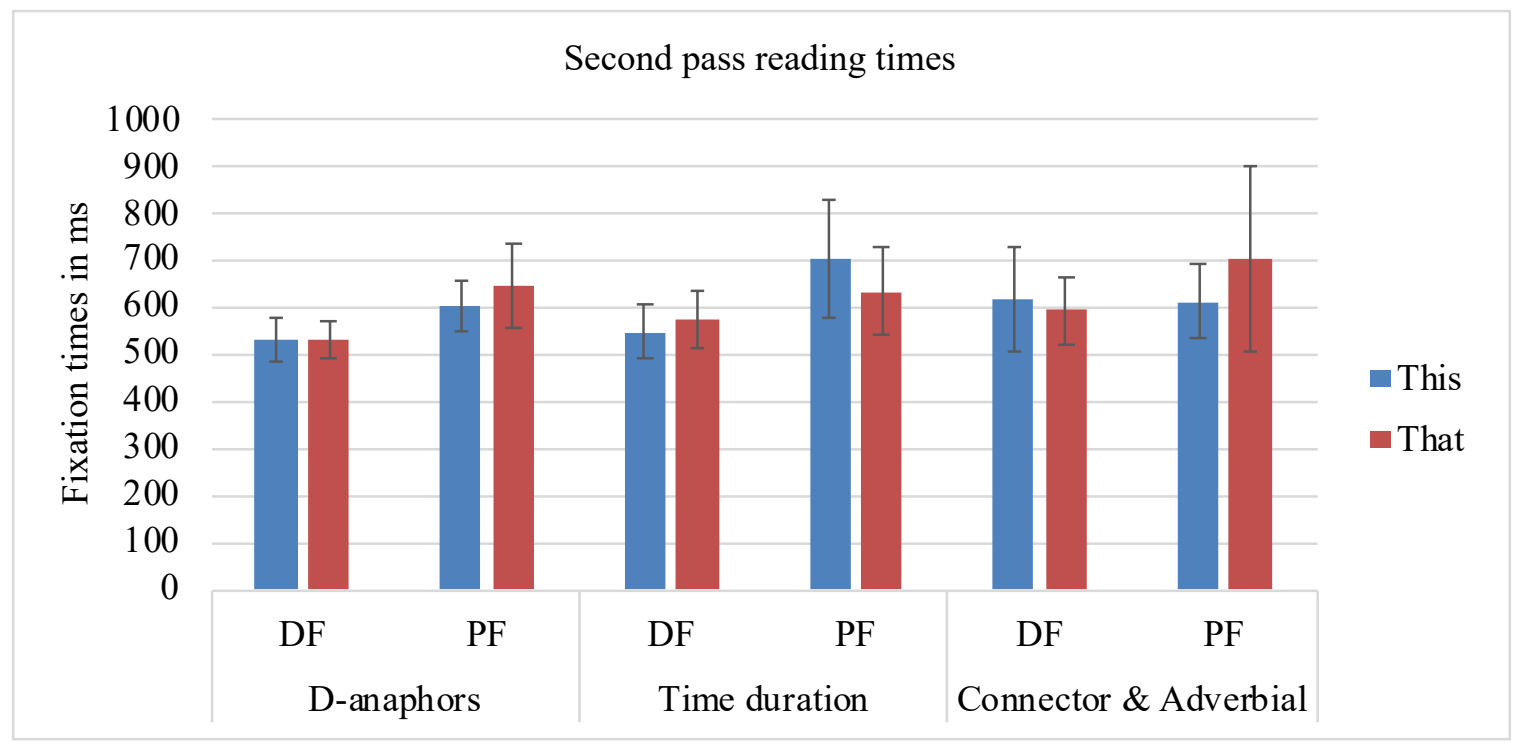

Figure 7. Second pass reading times (ms) across regions, for Experiment 3. Error bars show standard errors. 


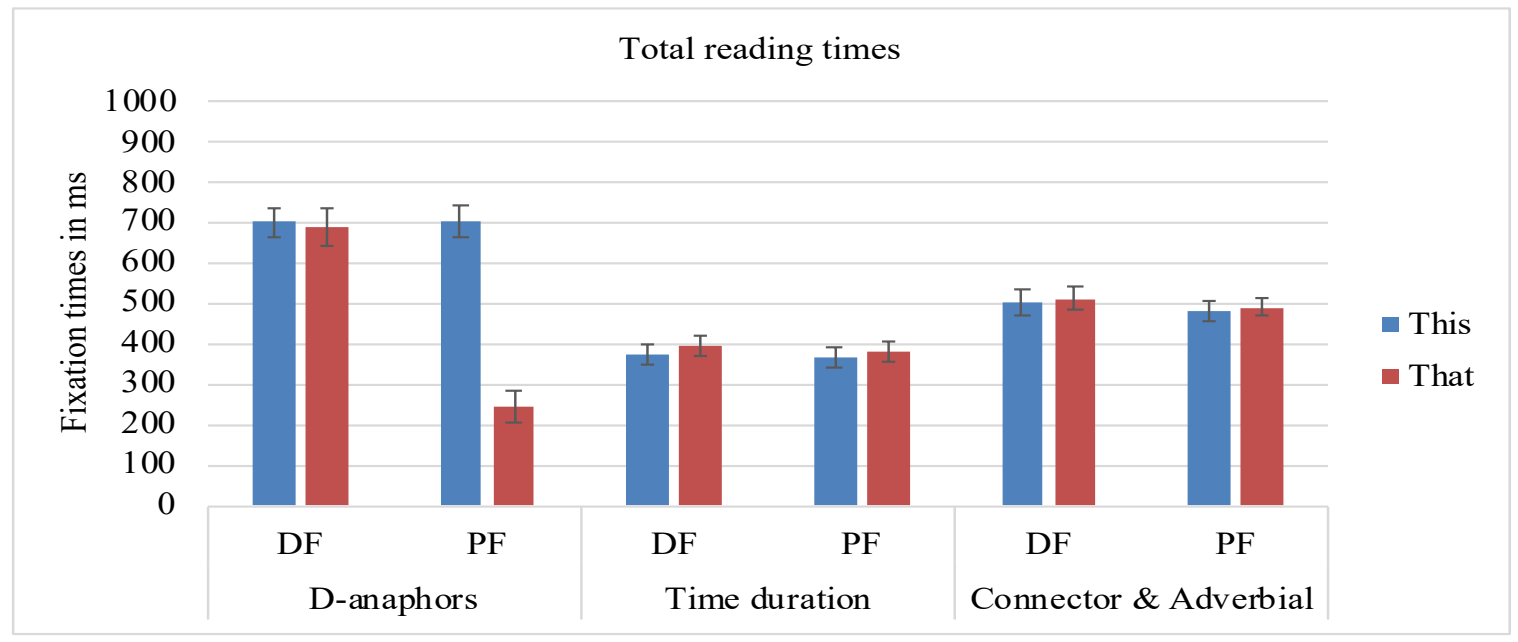

Figure 8. Total reading times (ms) across regions, for Experiment 3. Error bars show standard errors.

\subsection{Conclusion}

Experiment 3 was designed to test whether Turkish L2 readers would continue to show a preference for reference to the event on the PF, when the relative positions of the "long" and "short" events were opposite from Experiment 2. If this was the case, we would expect similar results to those of L1 native readers reported by Çokal et al. (2014), namely evidence of processing difficulty when the d-anaphor referred to the event described on the DF, even though this event was now of "long" duration. However, in contrast to this prediction, Experiment 3 results showed no evidence of processing difficulty for reference to the DF. Therefore, based on the results of Experiments 2 and 3, we cannot rule out the possibility that Turkish L2 readers simply preferred descriptions of "short" time durations (e.g., five minutes) over "long" durations (e.g., five hours), and possibly did not fully resolve the d-anaphor during on-line reading of the text. In this experiment, there was no evidence that Turkish L2 learners used features of 'spatial-temporal', 'degree of focus' or 'prominence of discourse (i.e., recency strategy).

\section{General Discussion}

This study was designed to explore Turkish L2 speakers' preferences in establishing the referents of this and that. We investigated whether Turkish L2 learners would disambiguate referents of this and that and - if so - whether 'spatial-temporal features' or 'degree of focus' would affect their choice of referent, in both on-line and offline settings. We predicted that Turkish L2 speakers would not index 'degree of focus' encoded by this and that, but instead would rely upon 'spatial-temporal features' in accordance with McCarthy's (1994) proximal-distal model. Secondly, we assumed L2 learners' preferences could change across on-line and offline experiments and their referent preferences would likely be clearer in the offline sentence completion experiment than the on-line eye-tracking experiment. In addition, we predicted that in an offline task (but not an on-line experiment), we could observe L1 interference. We also predicted that in an on-line task (i.e., on-line reading experiment), L2 learners would not use 'spatial-temporal features' of this and that, 'degree of focus', or recency strategy to disambiguate this/that. If this is the case, then we surmised that L2 learners would have on-line processing deficits and disadvantages. Alternatively, we also considered the possibility that, like the L1 English speakers in Çokal et al. (2014), Turkish L2 speakers' processing difficulty would be greater (reading times would be longer) and they would consider the prominence of discourse structure (i.e., recency strategy) if the distal frontier was inaccessible to references with this and that. 
Our first prediction was that Turkish L2 speakers would rely upon 'spatial-temporal features' in accordance with the proximal-distal model to determine the referents of d-anaphors. This was robustly supported in the sentence-completion experiment but in our on-line reading experiments, we could not find evidence that Turkish L2 learners were employing McCarthy's (1994) 'spatialtemporal' model or Strauss' (2002) 'degree of focus' model to disambiguate the referents of danaphors. In Experiment 1 (i.e., sentence completion experiment), when Turkish L2 learners were asked to refer to a certain part of a text with this and that, they preferred that when referring to a distal/less salient event/entity on the distal frontier and this in reference to a proximal/salient event/entity on the proximal frontier. Thus, there were contrasting distal and proximal frontier preferences for this and that between L1 and L2 speakers. In Çokal et al. (2014), L1 English speakers used degree of focus, which means this was used as an attention-caller to ask for high attention from an addressee when referring to less salient/distal elements on the distal frontier. On the other hand, that was used to refer to the referent/information on the proximal frontier/recent segment. However, Turkish L2 learners seemed to rely upon Turkish d-anaphors in written discourse (i.e., L1 interference): this/bu refers to a salient entity/event on the proximal frontier, whereas that/o refers to a less salient/distal entity/event on the distal frontier. In addition, that might be mapped onto both $o$ and şu in spoken discourse and therefore - for Turkish L2 learners - that can be more deictically marked than this when referring to a distal element, functioning like an "attention-caller" to specify reference. ${ }^{10}$ As was suggested by a reviewer of this manuscript, another possible explanation might be that our L2 participants transferred what they knew about deictic use of this and that and implemented it in a discourse anaphora context. Importantly, their preference pattern is consistent with the Turkish d-anaphora system and deictic features.

We also predicted that if Turkish L2 learners do not use 'spatial-temporal' or 'degree of focus' to determine referents of d-anaphors, then they would have a general preference of an event on the PF as a referent of this and that. In other words, similar to L1 English speakers (Çokal et al., 2014), Turkish L2 speakers' processing difficulty would be greater (and thus reading times longer) if the DF was inaccessible to references with this and that. In on-line reading, multiple eye-movement measures of L1 English speakers have shown an overall bias towards interpreting this and that when referring to the PF (Çokal et al., 2014). Çokal et al. (2014) interpreted this as a recency strategy in online reading. Alternatively, it could be interpreted as native speakers' preferences for this/that referring to the combined event/an entire paragraph (e.g., driving from Istanbul to Zonguldak + filling up car with petrol). Our Experiment 2 (i.e., on-line reading experiment) showed some evidence in favour of this interpretation, since Turkish L2 speakers showed longer second pass reading times when the d-anaphor was disambiguated to refer to the DF, relative to the proximal frontier. However, it should be noted this finding was found in only one measure and was not replicated in Experiment 3. Therefore, we did not find strong evidence for a recency strategy in on-line reading or the interpretation of the entire paragraph. The Turkish L2 learners' nontarget pattern (i.e., not having a consistent bias for PF references), or not using spatial-temporal features, might be because they did not effectively track the referents of this and that during on-line reading, although we also acknowledge that the on-line experiments may have lacked the power to detect the relevant effects in a noisy sample of L2 reading. ${ }^{11}$ Alternatively, if their nontarget pattern reflects an 'L2 on-line processing deficiency/disadvantage', it is consistent with previous L2 studies that found L2 learners did not integrate all information in on-line reading (Roberts et al., 2009; Wilson et al., 2009).

We also assumed that our L2 learners could have a different pattern/performance in the sentence completion experiment, compared to the on-line comprehension experiments. Our

\footnotetext{
${ }^{10}$ Referential expressions direct the reader to new entities or topics that are not highly salient.

${ }^{11}$ Hopp (2014) tested L2 readers processing of syntactic ambiguities and showed that there was an on-line preference only for readers who had a high lexical automaticity score (based on lexical decision times). The participants who had a lower automaticity score showed no significant difference.
} 
findings support this. Not only did the sentence completion task force L2 learners to have referent preferences for d-anaphors, but we also found a pattern consistent with L1 interference. On the other hand, in the on-line experiment, readers were not forced to make a decision regarding referents, and this might have been why it was difficult to find on-line evidence for L2 learners' preferences for this/that. These differences across tasks might indicate that L2 learners were not sure enough of their preference to generate reading difficulty in the reading experiment. In other words, Turkish L2 speakers may have been open to different configurations they found in the text because they were still 'learning'. However, L1 speakers' preferences in the on-line task in Çokal et al (2014) were much clearer, and these readers' fixation times showed evidence of processing difficulty when a reference went in an unexpected direction.

Regarding our main question of whether Turkish L2 speakers can acquire native-like interpretive preferences of d-anaphors, our sentence completion experiment showed that Turkish L2 learners' use of 'prominence of discourse structure' in the use of this and that' was quantitatively similar to that of English native speakers in Çokal et al. (2014). Both language groups preferred a salient/recent event on the PF as a referent of this and that while completing sentences. In addition, similarly to English native speakers (Çokal et al. 2014), Turkish L2 learners' completions showed evidence of sensitivity to this and that bringing different entities/events into focus and referring to different discourse frontiers. However, the difference between English native speakers in Çokal et al. (2014) and Turkish L2 speakers in the current study was their indexing degree of focus. Our findings support Niimura \& Hayashi (1996), in which L2 speakers did not index degree of focus. Such differences between Turkish L2 learners and English native speakers are due to L1 interference.

While Turkish L2 speakers' on-line reference resolution in reading experiments might be different from those of English native speakers, much more compelling evidence for the L2 speakers' recency preference came from the data in the sentence completion experiment. Methodologically, the overall pattern of findings suggests that the sentence completion method is a more sensitive measure of L2 reference representation than an on-line measure (such as eyetracking).

In this study, we did not explore the role of cognitive measures (e.g., working memory) in processing of d-anaphors in Turkish. We also did not investigate the role of different language proficiency levels or language instruction, as well as age, in processing and production of danaphors. These are further research avenues to explore.

\section{Acknowledgements}

The project was funded by OYP and the Scientific and Technological Research Council of Turkey (TUBITAK), Grant No. 108K405 and the ERC, grant number 695662. We would also like to thank the reviewers and journal editor for their valuable feedback. 


\section{Appendix A:}

1. Since English native speaker results are taken from Experiment 1A of Çokal et al. (2014), statistical information from that paper is repeated here for comparison purposes. In $14 \%$ of cases, this and that were used prenominally (e.g., this boy), or their antecedents were unclear. The proportion of these trials (coded as other) did not differ between this and that conditions $(Z=-1.33, p=.18)$. Native speakers preferred PF references. There was a significant effect of condition $(\widehat{\beta}=0.696, Z=3.12, p=.001)$. L1 speakers had more proximal frontier reference for that than for this (This $\mathrm{PF}=78 \%$, That $\mathrm{PF}=84 \%$ ). This, not that, was used to access entities/propositions on the distal frontier (This DF $=22 \%$ and That $\mathrm{DF}=16 \%$ ). Prenominal that $+\mathrm{NP}$ was used more frequently to refer to events on the distant or proximal frontier than this $+\mathrm{NP}(\mathrm{DF}$ : this $+\mathrm{NP}=10.8 \%$, that $+\mathrm{NP}=15.3 \%$; $\mathrm{PF}$ : this $+\mathrm{NP}=9.9 \%$, that $+\mathrm{NP}=15.3 \%$ ).

2. In Çokal et al. (2014), native speakers' data were reported using repeated- measures ANOVA treating d-anaphors (this-that) and frontiers (distal/proximal frontiers [DF/PF]) as within-participant and within-item analysis.

(1) Here, we briefly report the same native speakers' data in linear-mixed effect model to compare native and non-native speakers' preferences. In second-pass reading times, for the $\mathrm{d}$-anaphors region (R1), a main effect of frontier was significant $(\widehat{\beta}=-0.090, \mathrm{SE}=0.041, \mathrm{t}$ $=-2.178)$. Second pass reading time were longer than for the proximal frontier $(\mathrm{DF}=139$ $\mathrm{ms}, \mathrm{SE}=12.140 ; \mathrm{PF}=109 \mathrm{~ms}, \mathrm{SE}=9.688$ ) when this and that referred to the long event on the distal frontier. However, a main effect of d-anaphors and the interaction between these two factors were not significant (Intercept: $\widehat{\beta}=5.754$, $\mathrm{SE}=0.047, \mathrm{t}=122.071$; Danaphors: $\widehat{\beta}=0.013, \mathrm{SE}=0.044, \mathrm{t}=0.297$, D-anaphors $\mathrm{x}$ Frontiers: $\widehat{\beta}=0.036, \mathrm{SE}=0.081$, $\mathrm{t}=0.448)$.

(2) For the region of d-anaphors (R1), a main effect of discourse frontier was significant $(\widehat{\beta}=$ $0.085, \mathrm{SE}=0.027, \mathrm{t}=-3.112$ ) in total reading times. When this and that referred to the long event on the distal frontier (e.g., driving from Edinburgh to Birmingham), total reading times were longer than for the proximal frontier (e.g., filling up the car with petrol) $(\mathrm{DF}=524 \mathrm{~ms}, \mathrm{SE}=28.942 ; \mathrm{PF}=478 \mathrm{~ms}, \mathrm{SE}=26.282)$. A main effect of d-anaphors and the interaction between these two factors were not significant (Intercept: $\widehat{\beta}=6.019, \mathrm{SE}=$ 0.052, $\mathrm{t}=115.63$; D-anaphors: $\widehat{\beta}=0.029, \mathrm{SE}=0.022, \mathrm{t}=1.304$, D-anaphors $\mathrm{x}$ Frontiers: $\widehat{\beta}=0.003, \mathrm{SE}=0.044, \mathrm{t}=0.085$ ).

3. In second pass reading times, for the region of duration (R2), a main effect of frontier was found (Intercept: $\widehat{\beta}=342.79, \mathrm{SE}=29.38, \mathrm{t}=11.667$, Frontier: $\widehat{\beta}=-64.37, \mathrm{SE}=33.62, \mathrm{t}=\mathrm{-}$ 2.115; D-anaphors: $\widehat{\beta}=-38.85, \mathrm{SE}=31.17, \mathrm{t}=-1.247$, D-anaphors $X$ Frontiers: $\widehat{\beta}=61.46$, $\mathrm{SE}=44.01, \mathrm{t}=1.397)$. Regardless of whether this or that was used, references to events on the distal frontier led to longer second pass reading times than to events on the proximal frontier $(\mathrm{DF}=139 \mathrm{~ms}, \mathrm{SE}=12.140 ; \mathrm{PF}=109 \mathrm{~ms}, \mathrm{SE}=9.688$. $)$

(3) In total reading times, for the region of time duration (R2), a main effect of frontier was found $(\hat{\beta}=-32.146, \mathrm{SE}=14.836, \mathrm{t}=-2.167)$. Total reading times were longer when this and that referred to the short event on the $\mathrm{DF}(\mathrm{DF}=336, \mathrm{SE}=14.142 ; \mathrm{PF}=305, \mathrm{SE}=$ 9.553). A main effect of $d$-anaphors and an interaction between these factors were not significant (Intercept: $\widehat{\beta}=316.288, \mathrm{SE}=16.171, \mathrm{t}=19.559, \mathrm{D}$-anaphors: $\widehat{\beta}=-3.939, \mathrm{SE}=$ $14.454, \mathrm{t}=-0.272$, D-anaphors $X$ Frontiers: $\widehat{\beta}=6.728, \mathrm{SE}=27.433, \mathrm{t}=-2.167)$. In the connector and adverbial regions (R3), the same effect of frontier was seen (Intercept: $\widehat{\beta}=$ 5.84, $\mathrm{SE}=0.047, \mathrm{t}=122.607$, Frontier: $\widehat{\beta}=-0.036, \mathrm{SE}=0.022, \mathrm{t}=-1.634$; D-anaphors: $\widehat{\beta}=$ $-0.078, \mathrm{SE}=0.028, \mathrm{t}=-2.779$, D-anaphors $X$ Frontiers: $\widehat{\beta}=0.032, \mathrm{SE}=0.042, \mathrm{t}=0.761$, $\mathrm{DF}: \mathrm{DF}=417, \mathrm{SE}=15.57 ; \mathrm{PF}=377, \mathrm{SE}=13.39)$ 


\section{Appendix B: Stimuli for Experiment 1}

1A/1B. Berk drove from Istanbul to Zonguldak, listening to his favourite jazz CDs. When he arrived in Zonguldak, he filled up the car with petrol. This/That...

2A/2B. Berra packed her belongings with the help of her best friend. Once she had wrapped everything, she put the packages in her small car with great care. This/That...

3A/3B. Ceren moved to her new flat, taking all her belongings in one handbag and three suitcases. After she arrived, she called her mother with her Blackberry. This/That...

4A/4B. Sena went to the hairdresser, hoping to get the latest hairstyle. When she was at the hairdresser, she looked through the magazines for inspiration. This/That...

5A/5B. Mehmet ate his meal, annoyed that there was no beer. After he finished eating, he helped his girlfriend to prepare coffee with Sco:ttish whisky and cream. This/That...

$6 \mathrm{~A} / 6 \mathrm{~B}$. Ali prepared roast turkey and potatoes for his dinner party, planning to have drinks with the meal. After roasting the turkey, he prepared a Caesar salad. This/That...

7A/7B. Eren reorganised the seating plan, considering the $\mathrm{PhD}$ students' seating preferences. After he arranged the new seating plans in the offices, he went to his office on the first floor to have a strong coffee with whipped cream. This/That...

$8 \mathrm{~A} / 8 \mathrm{~B}$. Beytullah planted 50 roses, following all the instructions on the plant packaging. After he planted the roses with great care, he watered them with a watering can. This/That...

9A/9B. Samet flew back from Edinburgh to Turkey, travelling with his wife. When he arrived at Ataturk, he went to the Duty Free Shop to buy whisky for his father-in law. This/That...

10A/10B. Melisa baked a cake and some scones, following the recipe in Ceyhan's Kitchen. After she finished the scones, she washed the dishes on the counter. This/That...

11A/11B. Arda studied for the chemistry exam, worrying about the problems he might have to solve the next day. After he revised all the topics, he had a hot shower. This/That...

12A/12B. Alev prepared her third-year project, feeling anxious about not finishing $\backslash n i t$ on time. After she finished writing up the project, she submitted it to her instructor. This/That...

13A/13B. Sude did some spring cleaning at her flat, feeling surprised at how quickly it got dirty. After she cleaned the whole flat, she prepared a pasta salad for dinner. This/That...

14A/14B. Neslihan had an intense workout at CSE Gym in Istanbul, working with her trainer. After she completed her workout routine, she went to the sauna with her CD player. This/That...

15A/15B. Irmak went to the dentist with toothache on Monday morning, feeling uncomfortable from the pain. When she got there, she had to have the tooth out. This/That...

16A/16B. Hasan did his weekly shopping, picking up all the goods on the shopping list. When he arrived back at his flat, he put the groceries into the fridge and cupboards. This/That...

17A/17B. Nagehan swam in the swimming pool, pleased to know that she was burning some calories and staying fit. When she went to the changing room, she had a shower. This/That...

18A/18B. Ata wrote his book entitled Eye-tracking compiling all his experiences. After he finished writing up the chapters, he designed the cover page of his book using Photoshop. This/That...

19A/19B. Korhan washed his Peugeot 4007, listening to Capital FM. After he cleaned the outside of his car, he vacuumed the floor including the area beneath the seats. This/That...

20A/20B. Baturay drove from Edirne to Gaziantep, admiring the scenery on the way. When he arrived in Gaziantep, he looked for a cheap restaurant to have dinner. This/That...

$21 \mathrm{~A} / 21 \mathrm{~B}$. Furkan went to his friend's party on Friday night, taking two bottles of wine and a tub of ice-cream with him. Once the party was over, he took a taxi home. This/That...

$22 \mathrm{~A} / 22 \mathrm{~B}$. Nurbanu experienced a problem with the printer, worried that she would miss the deadline for her project. After she unsuccessfully tried to fix it, she went to the staff office in the basement to get help from one of the servitors. This/That...

23A/23B. Nevreste picked strawberries, helping her uncle and his workers. After she picked them, she walked to her uncle's house with her uncle and the workers. This/That... 
24A/24B. Sevilay rode her bike from her flat to work, singing a song. When she arrived at the bike rack, she bought some tea and cookies from the Sun Canteen. This/That...

25A/25B. Can climbed Kizlarsivrisi with his friends, using his climbing gear. When he reached the top, he ate his food with two bottles of fresh orange juice. This/That...

26A/26B. Deren walked around Istanbul, enjoying the blue sky and brisk wind. When she stopped at the Galata Tower, she had a bite to eat and drank mint tea. This/That...

27A/27B. Nurhayat had a health checkup on Women's Check-up Day, including screening, bone density and blood tests. After she finished her planned tests at Memorial Hospital, she visited her doctor with her husband and daughter. This/That...

28A/28B. Ekrem had a lovely breakfast with his family, enjoying the sun outside. After he had eaten the delicious breakfast, he went to the toilet with the newspaper. This/That...

29A/29B. Goncay played squash with her ex-boyfriend, hoping that she would beat him as she had in the old days. After the game, she did her routine stretching. This/That...

30A/30B. Behiye watched her favorite TV show Heroes, relaxing on her sofa. After she watched the final episode, she prepared a face mask with a little milk and avocado. This/That...

31A/31B. Sabutay argued with his wife about their financial problems, hoping that the children would not hear. After the argument, he had a hot shower to calm down. This/That...

32A/23B. Bilge had face-to-face meetings with her clients, highlighting the new product features. Before she left her office, she visited the ladies room downstairs. This/That...

33A/33B. Cendel reorganised some files in his office, planning to make space for his new books and files. While he was moving them, he read one of the documents. This/That...

34A/34B. Nisa enjoyed a camping trip in Fethiye, leaving all the stress of work and family behind her. When she got back home, she read her emails and letters. This/That...

35A/35B. Deniz went for a morning run in the new city, not knowing her way around. When she realized that she was not on the right road, she bought a map from the newsagents. This/ That...

36A/36B. Semirramis waited for the response from her job application, hoping to hear back soon. While she was waiting, she visited her cousin in Geneva. This/That...

37A/37B. Emircan held a house party, having heard his parents would be gone for the night. When his party ended, he washed all the wine glasses and plates by himself. This/That...

38A/38B. Ece flew from Ankara to New York, excited to be a PhD student. When she landed at Kennedy Airport, she experienced a problem at passport control. This/That...

39A/39B. Bircan went shopping for a wedding dress in Suadiye, wishing to find the dress of her dreams. When she found it, she phoned her bridesmaid to describe it. This/That...

40A/40B. Ada baked a cake for her friend's party, following her favourite recipe. After she baked it, she set the oven timer following the instruction manual. This/That... 


\section{Appendix C: Stimuli for Experiment 2}

1A/1B. Berk drove from Istanbul to Zonguldak, listening to his favourite jazz CDs. When he arrived in Zonguldak, he filled up the car with petrol. This/That took him 5 hours, and afterwards he was happy to have enough time to go to his hotel to have a rest.

$1 \mathrm{C} / 1 \mathrm{D}$. Berk drove from Istanbul to Zonguldak, listening to his favourite jazz CDs. When he arrived in Zonguldak, he filled up the car with petrol. This/That took him 5 minutes, and afterwards he was happy to have enough time for coffee.

2A/2B. Berra packed her belongings with the help of her best friend. Once she had wrapped everything, she put the packages in her small car with great care. This/That took her 3 hours, and subsequently she was pleased to have finished everything on time.

$2 \mathrm{C} / 2 \mathrm{D}$. Berra packed her belongings with the help of her best friend. Once she had wrapped everything, she put the packages in her small car with great care. This/That took her 8 minutes, and subsequently she was pleased to have fitted them all into her car.

3A/3B. Ceren moved to her new flat, taking all her belongings in one handbag and three suitcases. After she arrived, she called her mother with her Blackberry. This/That took her 5 hours, and afterwards she was too tired to unpack her suitcases.

$3 \mathrm{C} / 3 \mathrm{D}$. Ceren moved to her new flat, taking all her belongings in one handbag and three suitcases. After she arrived, she called her mother with her Blackberry. This/That took her 5 minutes, and afterwards she was too tired to call her boyfriend.

4A/4B. Sena went to the hairdresser, hoping to get the latest hairstyle. When she was at the hairdresser, she looked through the magazines for inspiration. This/That took her 2 hours, and then she was happy to get the hairstyle she desired.

4C/4D. Sena went to the hairdresser, hoping to get the latest hairstyle. When she was at the hairdresser, she looked through the magazines for inspiration. This/That took her 10 minutes, and then she was happy to find the hairstyle she wanted in one of the magazines.

5A/5B. Mehmet ate his meal, annoyed that there was no beer. After he finished eating, he helped his girlfriend to prepare coffee with Scottish whisky and cream. This/That took him 2 hours, and thereafter he was pleased that he had spent the evening with her.

$5 \mathrm{C} / 5 \mathrm{D}$. Mehmet ate his meal, annoyed that there was no beer. After he finished eating, he helped his girlfriend to prepare coffee with Scottish whisky and cream. This/That took him 15 minutes, and thereafter he was pleased that he had some whisky in his coffee.

6A/6B. Ali prepared roast turkey and potatoes for his dinner party, planning to have drinks with the meal. After roasting the turkey, he prepared a Caesar salad. This/That took him 2 hours, and eventually he was happy to finish it earlier than he expected.

$6 \mathrm{C} / 6 \mathrm{D}$. Ali prepared roast turkey and potatoes for his dinner party, planning to have drinks with the meal. After roasting the turkey, he prepared a Caesar salad. This/That took him 15 minutes and eventually he was happy to finish making the salad earlier than he expected.

7A/7B. Eren reorganised the seating plan, considering the PhD students' seating preferences. After he arranged the new seating plans in the offices, he went to his office on the first floor to have a strong coffee with whipped cream. This/That took him 2 hours, and subsequently he was annoyed about the students' never-ending requests.

7C/7D. Eren reorganised the seating plan, considering the PhD students' seating preferences. After he arranged the new seating plans in the offices, he went to his office on the first floor to have a strong coffee with whipped cream. This/That took him 10 minutes, and subsequently he was annoyed about resuming his work.

8A/8B. Beytullah planted 50 roses, following all the instructions on the plant packaging. After he planted the roses with great care, he watered them with a watering can. This/That took him 2 hours, and afterwards he was glad to finish the hard work 
$8 \mathrm{C} / 8 \mathrm{D}$. Beytullah planted 50 roses, following all the instructions on the plant packaging. After he planted the roses with great care, he watered them with a watering can. This/That took him 10 minutes, and afterwards he was glad to have time for his visit to the dentist.

9A/9B. Samet flew back from Edinburgh to Turkey, travelling with his wife. When he arrived at Ataturk, he went to the Duty Free Shop to buy whisky for his father-in law. This/That took him 5 hours, and eventually he was happy to arrive home.

9C/9D. Samet flew back from Edinburgh to Turkey, travelling with his wife. When he arrived at Ataturk, he went to the Duty Free Shop to buy whisky for his father-in law. This/That took him 15 minutes, and eventually he was happy to catch his next flight on time.

10A/10B. Melisa baked a cake and some scones, following the recipe in Ceyhan's Kitchen. After she finished the scones, she washed the dishes on the counter. This/That took her 2 hours, and therefore she was too tired to clean the flat.

10C/10D. Melisa baked a cake and some scones, following the recipe in Ceyhan's Kitchen. After she finished the scones, she washed the dishes on the counter. This/That took her 15 minutes, and therefore she was too tired to prepare the icing.

11A/11B. Arda studied for the chemistry exam, worrying about the problems he might have to solve the next day. After he revised all the topics, he had a hot shower. This/That took him 10 hours, and afterwards he was glad to be able to go to cinema.

$11 \mathrm{C} / 11 \mathrm{D}$. Arda studied for the chemistry exam, worrying about the problems he might have to solve the next day. After he revised all the topics, he had a hot shower. This/That took him 15 minutes, and afterwards he was glad to get an early night before the exam.

12A/12B. Alev prepared her third-year project, feeling anxious about not finishing $\backslash$ nit on time. After she finished writing up the project, she submitted it to her instructor. This/That took her 1 month, and naturally she was no longer worried about the project deadline.

$12 \mathrm{C} / 12 \mathrm{D}$. Alev prepared her third-year project, feeling anxious about not finishing it on time. After she finished writing up the project, she submitted it to her instructor. This/That took her 1 hour, and naturally she was no longer worried about taking a night off.

13A/13B. Sude did some spring cleaning at her flat, feeling surprised at how quickly it got dirty. After she cleaned the whole flat, she prepared a pasta salad for dinner. This/That took her 8 hours, and afterwards she was happy to have finished everything in one day.

13C/13D. Sude did some spring cleaning at her flat, feeling surprised at how quickly it got dirty. After she cleaned the whole flat, she prepared a pasta salad for dinner. This/That took her 40 minutes, and afterwards she was happy to have finished preparing her dinner for the night.

14A/14B. Neslihan had an intense workout at CSE Gym in Istanbul, working with her trainer. After she completed her workout routine, she went to the sauna with her CD player. This/That took her 2 hours, and thereafter she was happy to have relaxed before her meetings later in the day.

14C/14D. Neslihan had an intense workout at CSE Gym in Istanbul, working with her trainer. After she completed her workout routine, she went to the sauna with her CD player. This/That took her 15 minutes, and thereafter she was happy to have a cold shower.

15A/15B. Irmak went to the dentist with toothache on Monday morning, feeling uncomfortable from the pain. When she got there, she had to have the tooth out. This/That took her 2 hours, and later she was happy she would not have to go to work that day.

$15 \mathrm{C} / 15 \mathrm{D}$. Irmak went to the dentist with toothache on Monday morning, feeling uncomfortable from the pain. When she got there, she had to have the tooth out. This/That took her 15 minutes, and later she was happy she would not be in pain anymore.

16A/16B. Hasan did his weekly shopping, picking up all the goods on the shopping list. When he arrived back at his flat, he put the groceries into the fridge and cupboards. This/That took him 2 hours, and subsequently he was pleased to have a beer while watching some football.

$16 \mathrm{C} / 16 \mathrm{D}$. Hasan did his weekly shopping, picking up all the goods on the shopping list. When he arrived back at his flat, he put the groceries into the fridge and cupboards. This/That took him 10 minutes, and subsequently he was pleased to start cooking the chicken and couscous. 
17A/17B. Nagehan swam in the swimming pool, pleased to know that she was burning some calories and staying fit. When she went to the changing room, she had a shower. This/That took her 2 hours, and consequently she was worried about missing the deadline of her project.

17C/17D. Nagehan swam in the swimming pool, pleased to know that she was burning some calories and staying fit. When she went to the changing room, she had a shower. This/That took her 10 minutes, and consequently she was worried about being late for her class.

18A/18B. Ata wrote his book entitled Eye-tracking compiling all his experiences. After he finished writing up the chapters, he designed the cover page of his book using Photoshop. This/That took him 10 months, and afterwards he was happy about the distribution of his book to all universities in the world.

18C/18D. Ata wrote his book entitled Eye-tracking compiling all his experiences. After he finished writing up the chapters, he designed the cover page of his book using Photoshop. This/That took him 2 days, and afterwards he was happy about his final design.

19A/19B. Korhan washed his Peugeot 4007, listening to Capital FM. After he cleaned the outside of his car, he vacuumed the floor including the area beneath the seats. This/That took him 2 hours, and shortly after he was proud of how quickly he cleaned the car.

19C/19D. Korhan washed his Peugeot 4007, listening to Capital FM. After he cleaned the outside of his car, he vacuumed the floor including the area beneath the seats. This/That took him 10 minutes, and shortly after he was proud of how clean the inside of his car was.

20A/20B. Baturay drove from Edirne to Gaziantep, admiring the scenery on the way. When he arrived in Gaziantep, he looked for a cheap restaurant to have dinner. This/That took him 20 hours, and afterwards he was happy to go to his hotel to sleep.

20C/20D. Baturay drove from Edirne to Gaziantep, admiring the scenery on the way. When he arrived in Gaziantep, he looked for a cheap restaurant to have dinner. This/That took him 1 hour, and afterwards he was happy to have eaten the spiciest meal of his life.

$21 \mathrm{~A} / 21 \mathrm{~B}$. Furkan went to his friend's party on Friday night, taking two bottles of wine and a tub of ice-cream with him. Once the party was over, he took a taxi home. This/That took him 6 hours, and afterwards he was happy to have been to the most enjoyable party of his life.

$21 \mathrm{C} / 2 \mathrm{D}$. Furkan went to his friend's party on Friday night, taking two bottles of wine and a tub of ice-cream with him. Once the party was over, he took a taxi home. This/That took him 10 minutes, and afterwards he was happy to have arrived back home without any trouble.

$22 \mathrm{~A} / 22 \mathrm{~B}$. Nurbanu experienced a problem with the printer, worried that she would miss the deadline for her project. After she unsuccessfully tried to fix it, she went to the staff office in the basement to get help from one of the servitors. This/That took her 45 minutes, and consequently she was anxious because she did not know the result of missing the deadline.

$22 \mathrm{C} / 22 \mathrm{D}$. Nurbanu experienced a problem with the printer, worried that she would miss the deadline for her project. After she unsuccessfully tried to fix it, she went to the staff office in the basement to get help from one of the servitors. This/That took her 10 minutes, and consequently she was anxious because she had left her work to the last minute.

23A/23B. Nevreste picked strawberries, helping her uncle and his workers. After she picked them, she walked to her uncle's house with her uncle and the workers. This/That took her 5 hours, and consequently she was fed up with the day she had had.

23C/23D. Nevreste picked strawberries, helping her uncle and his workers. After she picked them, she walked to her uncle's house with her uncle and the workers. This/That took her 15 minutes and consequently she was fed up with the bad jokes and stories from the workers on the way.

24A/24B. Sevilay rode her bike from her flat to work, singing a song. When she arrived at the bike rack, she bought some tea and cookies from the Sun Canteen. This/That took her 30 minutes, and therefore she was in hurry to get to her meeting with the head of the department.

$24 \mathrm{C} / 24 \mathrm{D}$. Sevilay rode her bike from her flat to work, singing a song. When she arrived at the bike rack, she bought some tea and cookies from the Sun Canteen. This/That took her 7 minutes, and therefore she was in hurry tolneat them before work. 
25A/25B. Can climbed Kizlarsivrisi with his friends, using his climbing gear. When he reached the top, he ate his food with two bottles of fresh orange juice. This/That took him 10 hours, and consequently he was overjoyed because of the sense of relief and achievement.

$25 \mathrm{C} / 25 \mathrm{D}$. Can climbed Kizlarsivrisi with his friends, using his climbing gear. When he reached the top, he ate his food with two bottles of fresh orange juice. This/That took him 15 minutes, and consequently he was overjoyed because his friends had not tried to drink his orange juice.

26A/26B. Deren walked around Istanbul, enjoying the blue sky and brisk wind. When she stopped at the Galata Tower, she had a bite to eat and drank mint tea. This/That took her 6 hours, and subsequently she was excited to show the photos of the trip to her family.

26C/26D. Deren walked around Istanbul, enjoying the blue sky and brisk wind. When she stopped at the Galata Tower, she had a bite to eat and drank mint tea. This/That took her 20 minutes, and subsequently she was excited to see some more new places.

27A/27B. Nurhayat had a health Checkup on Women's Check-up Day, including screening, bone density and blood tests. After she finished her planned tests at Memorial Hospital, she visited her doctor with her husband and daughter. This/That took her 4 days, and eventually she was glad to finish her checkups.

28A/28B. Ekrem had a lovely breakfast with his family, enjoying the sun outside. After he had eaten the delicious breakfast, he went to the toilet with the newspaper. This/That took him 2 hours, and eventually he was pleased to spend some time at home.

$28 \mathrm{C} / 28 \mathrm{D}$. Ekrem had a lovely breakfast with his family, enjoying the sun outside. After he had eaten the delicious breakfast, he went to the toilet with the newspaper. This/That took him 15 minutes, and eventually he was pleased to read his favourite column.

29A/29B. Goncay played squash with her ex-boyfriend, hoping that she would beat him as she had in the old days. After the game, she did her routine stretching. This/That took her 1 hour, and eventually she was cheerful to go and get a drink.

29C/29D. Goncay played squash with her ex-boyfriend, hoping that she would beat him as she had in the old days. After the game, she did her routine stretching. This/That took her 5 minutes, and eventually she was cheerful to return to the changing room.

30A/30B. Behiye watched her favorite TV show Heroes, relaxing on her sofa. After she watched the final episode, she prepared a face mask with a little milk and avocado. This/That took her 2 hours, and thereafter she was glad to have time to do whatever she liked.

30C/30D. Behiye watched her favorite TV show Heroes, relaxing on her sofa. After she watched the final episode, she prepared a face mask with a little milk and avocado. This/That took her 10 minutes, and thereafter she was glad to have her skin feel so smooth.

31A/31B. Sabutay argued with his wife about their financial problems, hoping that the children would not hear. After the argument, he had a hot shower to calm down. This/That took him 1 hour, and afterwards he was worried since he did not know how to reconcile it with her.

31C/31D. Sabutay argued with his wife about their financial problems, hoping that the children would not hear. After the argument, he had a hot shower to calm down. This/That took him 5 minutes and afterwards he was worried since he did not want to go over the same issue.

32A/23B. Bilge had face-to-face meetings with her clients, highlighting the new product features. Before she left her office, she visited the ladies room downstairs. This/That took her 6 hours and afterwards she was relieved to have finished her tiring day.

32C/32D. Bilge had face-to-face meetings with her clients, highlighting the new product features. Before she left her office, she visited the ladies room downstairs. This/That took her 10 minutes and afterwards she was relieved to have freshened up.

$33 \mathrm{~A} / 33 \mathrm{~B}$. Cendel reorganised some files in his office, planning to make space for his new books and files. While he was moving them, he read one of the documents. This/That took him 2 hours, and afterwards he was happy to have enough empty space for his new books. 
33C/33D. Cendel reorganised some files in his office, planning to make space for his new books and files. While he was moving them, he read one of the documents. This/That took him 13 minutes and afterwards he was happy to have read such an interesting document.

34A/34B. Nisa enjoyed a camping trip in Fethiye, leaving all the stress of work and family behind her. When she got back home, she read her emails and letters. This/That took her 2 days, and afterwards she was happy to feel strong enough to cope with all the challenges she faced.

34C/34D. Nisa enjoyed a camping trip in Fethiye, leaving all the stress of work and family behind her. When she got back home, she read her emails and letters. This/That took her 10 minutes and afterwards she was happy to go to bed early.

35A/35B. Deniz went for a morning run in the new city, not knowing her way around. When she realized that she was not on the right road, she bought a map from the newsagents. This/That took her 1 hour, and eventually she was pleased to arrive back home.

$35 \mathrm{C} / 35 \mathrm{D}$. Deniz went for a morning run in the new city, not knowing her way around. When she realized that she was not on the right road, she bought a map from the newsagents. This/That took her 3 minutes, and eventually she was pleased to be able to find her way more easily.

36A/36B. Semirramis waited for the response from her job application, hoping to hear back soon. While she was waiting, she visited her cousin in Geneva. This/That took her 2 months, and eventually she was pleased to have time to relax after her graduation from the university.

36C/36D. Semirramis waited for the response from her job application, hoping to hear back soon. While she was waiting, she visited her cousin in Geneva. This/That took her 10 days, and eventually she was pleased to have got away from her hometown.

37A/37B. Emircan held a house party, having heard his parents would be gone for the night. When his party ended, he washed all the wine glasses and plates by himself. This/That took him 7 hours, and subsequently he was too exhausted to even think about having another party in his parents' house again.

37C/37D. Emircan held a house party, having heard his parents would be gone for the night. When his party ended, he washed all the wine glasses and plates by himself. This/That took him 1 hour, and subsequently he was too exhausted to clean the floor.]

38A/38B. Ece flew from Ankara to New York, excited to be a PhD student. When she landed at Kennedy Airport, she experienced a problem at passport control. This/That took her 8 hours, and meanwhile she was angry with herself for not sleeping on the flight.

38C/38D. Ece flew from Ankara to New York, excited to be a PhD student. When she landed at Kennedy Airport, she experienced a problem at passport control. This/That took her 45 minutes, and meanwhile she was angry with herself for not bringing her acceptance letter.

39A/39B. Bircan went shopping for a wedding dress in Suadiye, wishing to find the dress of her dreams. When she found it, she phoned her bridesmaid to describe it. This/That took her 5 hours, and afterwards she was pleased because she still had time to schedule her hairdresser and photographer.

39C/39D. Bircan went shopping for a wedding dress in Suadiye, wishing to find the dress of her dreams. When she found it, she phoned her bridesmaid to describe it. This/That took her 10 minutes, and afterwards she was pleased because her bridesmaid also liked the dress.

40A/40B. Ada baked a cake for her friend's party, following her favourite recipe. After she baked it, she set the oven timer following the instruction manual. This/That took her 30 minutes, and consequently she was glad to have finished on time for the party.

40C/40D. Ada baked a cake for her friend's party, following her favourite recipe. After she baked it, she set the oven timer following the instruction manual. This/That took her 5 minutes, and consequently she was glad to. have understood the manual. 


\section{Appendix D: Stimuli for Experiment 3}

1A/1B. Berke filled up the car with petrol, being careful not to spill any over his white wedding trousers. Then he drove from Istanbul to Zonguldak. This/That took him 5 hours, and afterwards he was happy not to have had to stop on his way.

$1 \mathrm{C} / 1 \mathrm{D}$. Berke filled up the car with petrol, being careful not to spill any over his white wedding trousers. Then he drove from Istanbul to Zonguldak. This/That took him 5 minutes, and afterwards he was happy not to have stained his trousers.

$2 \mathrm{~A} / 2 \mathrm{~B}$. Berra phoned to book a taxi to the airport for $7 \mathrm{pm}$, becoming stressed by the busy operator. Afterwards, she packed her suitcases with all her holiday clothes. This/That took her 1 hour, and afterwards she was sad to be leaving the country.

$2 \mathrm{C} / 2 \mathrm{D}$. Berra phoned to book a taxi to the airport for $7 \mathrm{pm}$, becoming stressed by the busy operator. Afterwards, she packed her suitcases with all her holiday clothes. This/That took her 5 minutes, and afterwards she was sad to be leaving the country.

3A/3B Ceren had a quick coffee at the hairdresser's, surrounded by women gossiping about the city council. Then she had her hair restyled in one of the latest fashions. This/That took her 1 hour, and afterwards she was happy to have found the hairstyle she wanted in one of the magazines.

$3 \mathrm{C} / 3 \mathrm{D}$. Ceren had a quick coffee at the hairdresser's, surrounded by women gossiping about the city council. Then she had her hair restyled in one of the latest fashions. This/That took her 10 minutes, and afterwards she was happy to have her morning coffee with a catch up.

4A/4B. Mehmet had a look at the festival programme, hoping to find a play that grabbed him. Then he saw The Nihilists at the Ataturk Cultural Centre of Istanbul. This/That took him 2 hours, and afterwards he was happy to have watched a well-performed play.

4C/4D Mehmet had a look at the festival programme, hoping to find a play that grabbed him. Then he saw The Nihilists at the Ataturk Cultural Centre of Istanbul. This/That took him 20 minutes, and afterwards he was happy to have found something that he liked.

5A/5B. Yalman had his morning coffee catching up with new gossip in the department in the kitchen. After the coffee, he reorganised the seating plan in the PhD students' offices. This/That took him 2 hours, and afterwards he was pleased to have his lunch soon.

6A/6B. Beytullah read all the instructions from the garden centre, wearing his Dolce and Gabbana sunglasses. Then he planted 50 roses with great care and patience. This/That took him 2 hours, and afterwards he was delighted to have done so much hard work.

$6 \mathrm{C} / 6 \mathrm{D}$. Beytullah read all the instructions from the garden centre, wearing his Dolce and Gabbana sunglasses. Then he planted 50 roses with great care and patience. This/That took him 6 minutes, and afterwards he was delighted to have done some gardening.

7A/7B. Samet went to the Duty Free Shop to buy Turkish drinks and Turkish delights for his fatherin-law and workmates. Then he flew back from Turkey to Edinburgh. This/That took him 6 hours, and eventually he was happy to arrive home.

8A/8B. Melisa washed the dishes at the counter, listening to her favourite Rock CDs. Then she read the famous historian Fernand Braudel's writings on the Mediterranean. This/That took her 2 hours, and afterwards she was glad to start writing her thesis.

$8 \mathrm{C} / 8 \mathrm{D}$. Melisa washed the dishes at the counter, listening to her favourite Rock CDs. Then she read the famous historian Fernand Braudel's writings on the Mediterranean. This/That took her 25 minutes, and afterwards she was glad she had not left them until later.

9A/9B. Cemal had a shower, anxious about his sister and her new boyfriend. Then he studied for the maths and chemistry exams with his best friend from university. This/That took him 5 hours, and afterwards he was worried he had left his calculator at his ex-girlfriend's.

9C/9D. Cemal had a shower, anxious about his sister and her new boyfriend. Then he studied for the maths and chemistry exams with his best friend from university. This/That took him 5 minutes, and afterwards he was worried he had left the boiler on. 
10A/10B. Neslihan printed out her third-year essay to hand it in to her instructor, feeling anxious about not submitting it on time. Then she had a long soak in the bath to relax. This/That took her 1 hour, and afterwards she was relieved to have stopped worrying about the essay at last.

10C/10D. Neslihan printed out her third-year essay to hand it in to her instructor, feeling anxious about not submitting it on time. Then she had a long soak in the bath to relax. This/That took her 5 minutes, and afterwards she was relieved to have submitted it on time.

11A/11B. Irmak had breakfast with her boyfriend, listening to the Classical Collection from the 18th Century on BBC Radio 3. Then she did some spring cleaning at her flat. This/That took her 8 hours, and subsequently she was energetic enough to accomplish the other plans she had for the evening.

11C/11D. Irmak had breakfast with her boyfriend, listening to the Classical Collection from the 18th Century on BBC Radio 3. Then she did some spring cleaning at her flat. This/That took her 30 minutes, and subsequently she was energetic enough to start a new day.

12A/12B. Hazal had to have her tooth out, feeling uncomfortable because of her bad breath. Then she spent the rest of her day checking the company accounts. This/That took her 5 hours, and later she was glad she would not have fallen behind in her work.

$12 \mathrm{C} / 12 \mathrm{D}$. Hazal had to have her tooth out, feeling uncomfortable because of her bad breath. Then she spent the rest of her day checking the company accounts. This/That took her 10 minutes, and later she was glad she did not have smelly breath.

13A/13B. Aykut put the groceries into the fridge and cupboards, trying to be as tidy as he could. After he had put them away, he watched some rugby. This/That took him 2 hours, and subsequently he was pleased with the result of the match.

13C/13D. Aykut put the groceries into the fridge and cupboards, trying to be as tidy as he could. After he had put them away, he watched some rugby. This/That took him 10 minutes, and subsequently he was pleased to have finished unpacking so soon.

14A/14B. Nurbanu pulled over onto the hard shoulder to pick up a hitchhiker on a rainy day, realizing that it was a horrible day to be standing by the side of the road. Then she drove the car to her new company in a new city centre. This/That took her 1 hour, and afterwards she was glad to have been on time for her meeting.

14C/14D. Nurbanu pulled over onto the hard shoulder to pick up a hitchhiker on a rainy day, realizing that it was a horrible day to be standing by the side of the road. Then she drove the car to her new company in a new city centre. This/That took her 3 minutes, and afterwards she was glad to have done her good deed for the day.

15A/15B. Onur designed the cover of his book entitled Eye-tracking methods in linguistics, wishing it to be more appealing to buyers. Then he wrote the chapters. This/That took him 10 months, and afterwards he was confident since he had gathered all the recent studies in his chapters.

$15 \mathrm{C} / 15 \mathrm{D}$. Onur designed the cover of his book entitled Eye-tracking methods in linguistics, wishing it to be more appealing to buyers. Then he wrote the chapters. This/That took him 3 hours, and afterwards he was confident since his design would draw attention.

16A/16B. Yalman looked under all his car seats for his brother-in-law's brown leather wallet. Then he cleaned his Peugeot 308 inside and out. This/That took him 2 hours, and afterwards he was pleased with how bright and shiny his car looked.

16C/16D. Yalman looked under all his car seats for his brother-in-law's brown leather wallet. Then he cleaned his Peugeot 308 inside and out. This/That took him 10 minutes, and afterwards he was pleased to have found it.

17A/17B. Volkan looked for a cheap and clean restaurant before going on a trip with his partner. After his lunch, he drove from Gaziantep to Kayseri. This/That took him 6 hours, and afterwards he was happy to have arrived at his hotel to sleep.

18A/18B. Nevreste walked to her uncle's farm with her uncle and the workers, wishing she could finish the work quickly. After she had arrived at the farm, she picked strawberries. This/That took her 5 hours, and afterwards she was fed up with the day she had had. 
18C/18D. Nevreste walked to her uncle's farm with her uncle and the workers, wishing she could finish the work quickly. After she had arrived at the farm, she picked strawberries. This/That took her 15 minutes, and afterwards she was fed up with the bad jokes and stories from the workers on the way.

19A/19B. Cengiz took a taxi to his friend's flat, taking two bottles of wine and a tub of ice-cream with him. Then he sewed a thousand sequins onto his cowboy costume. This/That took him 2 hours, and afterwards he was glad to be the best-dressed cowboy at the party.

19C/19D. Cengiz took a taxi to his friend's flat, taking two bottles of wine and a tub of ice-cream with him. Then he sewed a thousand sequins onto his cowboy costume. This/That took him 10 minutes, and afterwards he was glad to see his friend again.

20A/20B. Dilruba went to the staff office in the basement to get help from/none of the technicians. Then she re-ran the experiment with a new participant. This/That took her 2 hours, and afterwards she was glad because she had finished the experiment on time.

20C/20D. Dilruba went to the staff office in the basement to get help from one of the technicians. Then she re-ran the experiment with a new participant. This/That took her 5 minutes, and afterwards she was glad because the technical problem was not serious.

21A/21B. Sevilay bought some bread and soup from Hocam Piknik next door, feeling too tired to cook at home. Then she rode her bike over to Mithatcan's in Karakusunlar. This/That took her 30 minutes, and afterwards she found that Mithatcan had also bought soup for dinner.

21C/21D. Sevilay bought some bread and soup from Hocam Piknik next door, feeling too tired to cook at home. Then she rode her bike over to Mithatcan's in Karakusunlar. This/That took her 5 minutes, and afterwards she found that the shopkeeper had given her too much change.

22A/22B. Karatay ate two sandwiches and a bar of Kendal mint cakes, enjoying the sun outside. Then he climbed KartalTepe with his sister and three friends. This/That took him 10 hours, and afterwards he was very pleased because his girlfriend would be waiting for him at base camp.

$22 \mathrm{C} / 22 \mathrm{D}$. Karatay ate two sandwiches and a bar of Kendal mint cakes, enjoying the sun outside. Then he climbed KartalTepe with his sister and three friends. This/That took him 15 minutes, and afterwards he was very pleased because his girlfriend had packed it for him.

23A/23B. Nurcan had a bite to eat and drank mint tea at the Galata Tower, enjoying the sunset and light wind. After the Galata Tower, she caught the overnight train to Eskisehir. This/That took her 6 hours, and afterwards she couldn't wait to get out and stretch her legs.

$23 \mathrm{C} / 23 \mathrm{D}$. Nurcan had a bite to eat and drank mint tea at the Galata Tower, enjoying the sunset and light wind. After the Galata Tower, she caught the overnight train to Eskisehir. This/That took her 20 minutes, and afterwards she couldn't wait to buy some mint tea to drink at home.

24A/24B. Nurhayat visited her doctor with her husband and daughter, worried she may have breast cancer. Then she had a long wait to hear the results of the tests. This/That took her 5 days, and afterwards she was glad to get the all-clear.

24C/24D. Nurhayat visited her doctor with her husband and daughter, worried she may have breast cancer. Then she had a long wait to hear the results of the tests. This/That took her 25 minutes, and afterwards she was glad she had had her family with her.

25A/25B. Samet went to the bathroom for a quick shower on Sunday morning, singing one of Elvis' songs. Then he had a leisurely breakfast with his family and next-door neighbours. This/That took him 2 hours, and afterwards he was pleased not to have gone out for breakfast with his friends.

$25 \mathrm{C} / 25 \mathrm{D}$. Samet went to the bathroom for a quick shower on Sunday morning, singing one of Elvis' songs. Then he had a leisurely breakfast with his family and next-door neighbours. This/That took him 10 minutes, and afterwards he was pleased not to have forgotten to cut his toenails.

26A/26B. Gonca did her routine stretching, hoping that she would beat her ex-boyfriend as she had in the old days. Then she played squash with him. This/That took her 1 hour, and afterwards she was raring to mock him. 
26C/26D. Gonca did her routine stretching, hoping that she would beat her ex-boyfriend as she had in the old days. Then she played squash with him. This/That took her 5 minutes, and afterwards she was raring to go.

27A/27B. Behiye prepared a hard boiled egg for her maternal grandmother's evening meal. Then she watched her favourite TV show Rosellinda and Annabel. This/That took her 50 minutes, and afterwards she was glad To have seen Brian and Rosellinda finally get together.

27C/27D. Behiye prepared a hard boiled egg for her maternal grandmother's evening meal. Then she watched her favourite TV show Rosellinda and Annabel. This/That took her 10 minutes, and afterwards she was glad she had remembered to buy the eggs.

28A/28B. Sabutay called BaskentGaz and Power to find out about their monthly payment, hoping not to pay much. After the call, he argued all evening with his wife about their financial problems. This/That took him 2 hours, and afterwards he was worried as he did not know how to make up with her.

28C/28D. Sabutay called BaskentGaz and Power to find out about their monthly payment, hoping not to pay much. After the call, he argued all evening with his wife about their financial problems. This/That took him 5 minutes, and afterwards he was worried as he did not know how to break the bad news to her.

29A/29B. Bahar visited the ladies room downstairs, wanting to start the day looking good. After the ladies room, she had face-to-face meetings with her new clients. This/That took her 6 hours, and afterwards she was relieved to have finished her tiring day.

29C/29D. Bahar visited the ladies room downstairs, wanting to start the day looking good. After the ladies room, she had face-to-face meetings with her new clients. This/That took her 10 minutes, and afterwards she was relieved to have freshened up.

30A/30B. Cendel noted down all the important documents his boss requested for the meeting, wishing not to forget any of them. Later he searched for them in all the files in his office. This/That took him 2 hours, and afterwards he was happy to be able to get ready for the meeting.

30C/30D. Cendel noted down all the important documents his boss requested for the meeting, wishing not to forget any of them. Later he searched for them in all the files in his office. This/That took him 5 minutes, and afterwards he was happy to have found them.

31A/31B. Banu read her emails and letters, happy that she would leave all the stress, work and family behind her soon. After reading them, she took a camping trip in Fethiye. This/That took her 2 days, and afterwards she was pleased to feel strong enough to cope with all the challenges she faced.

31C/31D. Banu read her emails and letters, happy that she would leave all the stress, work and family behind her soon. After reading them, she took a camping trip in Fethiye. This/That took her 5 minutes, and afterwards she was pleased to start her trip earlier than she expected.

32A/32B. Derya bought a map from the newsagents, worried that she was hopelessly lost. Then she tried to find her way back to the new company's regional offices. This/That took her 1 hour, and afterwards she was pleased to have arrived in time for the meeting.

32C/32D. Derya bought a map from the newsagents, worried that she was hopelessly lost. Then she tried to find her way back to the new company's regional offices. This/That took her 3 minutes, and afterwards she was pleased to have found one for only two pounds.

$33 \mathrm{~A} / 33 \mathrm{~B}$. Emircan prepared all the wine glasses and plates, guessing the number of people that would come around. Then he served four courses to his guests. This/That took him 3 hours, and afterwards he was too exhausted to think about having another dinner party in his flat again.

$33 \mathrm{C} / 33 \mathrm{D}$. Emircan prepared all the wine glasses and plates, guessing the number of people that would come around. Then he served four courses to his guests. This/That took him 20 minutes, and afterwards he was too exhausted to arrange everything on time.

34A/34B. Esra experienced a problem at the Turkish Airlines desk, nervous she would miss her direct flight. Then she flew from Istanbul to the United States. This/That took her 9 hours, and meanwhile she was very angry with herself for not sleeping on the flight. 
34C/34D. Esra experienced a problem at the Turkish Airlines desk, nervous she would miss her direct flight. Then she flew from Istanbul to the United States. This/That took her 45 minutes, and meanwhile she was very angry with herself for not bringing the credit card that she used to pay for her booking.

35A/35B. Asya phoned her bridesmaid to go shopping, wishing to find the dress she would like. Then she went shopping for a wedding dress in Armada in Ankara. This/That took her 5 hours, and afterwards she was pleased since she still had time to schedule her hairdresser and photographer.

$35 \mathrm{C} / 35 \mathrm{D}$. Asya phoned her bridesmaid to go shopping, wishing to find the dress she would like. Then she went shopping for a wedding dress in Armada in Ankara. This/That took her 10 minutes, and afterwards she was pleased since she would have a day with her bridesmaid.

36A/36B Ahu set the oven timer following the instruction manual. Then she made a cake with apricots and tarts with strawberries and blueberries for her friend's party. This/That took her 30 minutes, and eventually she was glad to have finished on time for the party.

36C/36D. Ahu set the oven timer following the instruction manual. Then she made a cake with apricots and tarts with strawberries and blueberries for her friend's party. This/That took her 10 minutes, and eventually she was glad to have understood the manual.

37A/37B. Durukan waited for the next train to Mersin, feeling tired after a long day in Adana. When he got the train, he had to sit with the largest man in Turkey. This/That took him 55 minutes, and afterwards he was irritated at having had such a long day.

37C/37D. Durukan waited for the next train to Mersin, feeling tired after a long day in Adana. When he got the train, he had to sit with the largest man in Turkey. This/That took him 10 minutes, and afterwards he was irritated about being in the ridiculously crowded train.

38A/38B. Asu travelled four stops on the tram, wishing to see the Ayasofya museum in Istanbul before 6 p.m. Then she visited the greatest museum. This/That took her 2 hours, and afterwards she was drained from looking at lots of mosaics.

$38 \mathrm{C} / 38 \mathrm{D}$. Asu travelled four stops on the tram, wishing to see the Ayasofya museum in Istanbul before 6 p.m. Then she visited the greatest museum. This/That took her 10 minutes, and afterwards she was drained because the train got very crowded.

39A/39B. Kenter stood in the footlights, revelling in the audience's applause. Then she had dinner with the sonata's composer, musicians and some journalists. This/That took her 2 hours, and afterwards she had never felt so full.

39C/39D. Kenter stood in the footlights, revelling in the audience's applause. Then she had dinner with the sonata's composer, musicians and some journalists. This/That took her 3 minutes, and afterwards she had never seen so many flowers thrown upon stage.

40A/40B. Yurdanur had a long interview for the M.Sc programme in biology, hoping she would be accepted. Then she visited her cousin and aunt in Geneva. This/That took her 15 days, and eventually she was pleased to have time to relax after finishing her undergraduate dissertation. 40C/40D. Yurdanur had a long interview for the M.Sc programme in biology, hoping she would be accepted. Then she visited her cousin and aunt in Geneva. This/That took her 25 minutes, and eventually she was pleased to have answered all questions asked to her. 


\section{References}

Altmann, G. T. M., \& Kamide, Y. (2007). The real-time mediation of visual attention by language and world knowledge: Linking anticipatory (and other) eye movements to linguistic processing. Journal of Memory and Language, 57(4): 502-518. https://doi.org/10.1016/j.jml.2006.12.004

Anderson, A., Garrod, S. C., \& Sanford, A. J. (1983). The accessibility of pronominal antecedents as a function of episode shifts in narrative text. The Quarterly Journal of Experimental Psychology Section A, 35(3): 427-440.

Anderson, S. R., \& Keenan, E. L. (1985). Deixis. Language Typology and Syntactic Description, 3(4): 259-308.

Ariel, M. (1996). Referring expressions and the $+/-$ coreference distinction. In T. Fretheim \& K. Gundel (Eds.), Reference and referent accessibility, pages 13-25, Amsterdam: John Benjamins.

Bates, D., Mächler, M., Bolker, B., \& Walker, S. (2015). Fitting Linear Mixed-Effects Models Using lme4. Journal of Statistical Software, 67(1): 1-48.

Barr, D. J., Levy, R., Scheepers, C., \& Tily, H. J. (2013). Random effects structure for confirmatory hypothesis testing: Keep it maximal. Journal of Memory and Language, 68(3):10.

Blagoeva, R. (2004). Demonstrative reference as a cohesive device in advanced learner writing: a corpus-based study. In K. Aijmer \& B. Altenberg (Eds.), Advances in corpus linguistics. Papers from the 23rd international conference on English language research on computerized corpora (ICAME 23), pages 297-307, Amsterdam \& New York: Rodopi.

Clahsen, H., \& Felser, C. (2006). Continuity and shallow structures in language processing. Applied Psycholinguistics, 27(01): 107-126. https://doi.org/10.1017/S0142716406060024

Cokal, D. (2021, March 5). L2 processing of d-anaphors. Retrieved from osf.io/v2msd

Çokal, D. (2019). Discourse Deixis and Anaphora in L2 Writing. Dilbilim Araşstırmaları, 30(02): 241-277. Boğaziçi Üniversitesi Yayınevi, İstanbul.

Çokal, D. (2010). The Pronominal bu-şu and this-that: Rhetorical structure theory. Dilbilim Araştırmaları, 1, 15-33.

Çokal, D., \& Ruhi, Ş. (2006). Discourse anaphors in L2 English writing: Implications for Researching Interlanguage Demonstrative Systems. Paper presented at the 16th Annual Conference of the European Second Language Association, Antalya, Turkey.

Çokal, D., Sturt, P., \& Ferreira, F. (2014). Deixis: This and that in written narrative discourse. Discourse Processes, 51(3): 201-229. doi: 10.1080/0163853X.2013.866484

Cornish, F., (2010). Anaphora: text-based or discourse-dependent? Functionalist vs. formalist accounts. Functions of Language, 17 (2): 207-241.

Cornish, F., (2009). Indexicality by degrees: Deixis, 'anadeixis' and (discourse) anaphora. Paper presented at a symposium (Quel sens pour la linguistique?) organized to mark the conferral of a doctorate honoris causa on Sir John Lyons, Université de Toulouse-Le Mirail, 23-24 April, 2009.

DeKeyser, R. (2003). Implicit and explicit learning. In M. Long and C. Doughtly (eds.). Handbook of second language acquisition, pages 313-348, Malden, MA: Blackwell.

Diessel, H. (2006). Demonstratives, joint attention, and the emergence of grammar. Cognitive Linguistics, 17: 463-489. doi: 10.1515/COG.2006.019

Ehrlich, K., \& Rayner, K. (1983). Pronouns assignment and semantic integration during reading: Eye-movements and immediacy of processing. Journal of Verbal Learning and Verbal Behavior, 22:75-87.

Elbourne, P. (2008). Demonstratives as individual concepts. Linguistics and Philosophy, 31:409466.

Ellert, M. (2013). Resolving ambiguous pronouns in a second language: A visual world eyetracking study with Dutch learners of German. International Review of Applied Linguistics in Language Teaching, 51:71-197. doi: 10.1515/iral-2013-0008 
Ellis, R. (2008). The study of second language acquisition. Oxford: Oxford University Press.

Ellis, N. (2015). Implicit and explicit language learning: Their dynamic interface and complexity. In Rebuschat, P. (ed.). Implicit and explicit learning of languages, pages 3-23, Amsterdam: John Benjamins.

Enç, M. (1986). "Topic switching and pronominal subjects in Turkish.” In D. I. Slobin and K. Zimmer (Eds.) Studies in Turkish Linguistics (pp.195-208). Amsterdam: John Benjamins. Erguvanl1-Taylan, E. (1986). Pronominal versus zero representation of anaphora in Turkish. In Dan. I. Slobin \& Karl Zimmer (Eds.). Studies in Turkish linguistics, pages 209-231, Amsterdam: John Benjamins.

Ferris, D. R. (1994). Lexical and syntactic features of ESL writing by students at different levels of L2 proficiency. TESOL Quarterly, 28(2): 414. doi: 10.2307/3587446

Fossard, M., \& Rigalleau, F. (2005). Referential accessibility and anaphora resolution: The case of the French hybrid demonstrative pronouns: Celui-ci/celle-ci. In A. Branco, T. McEnry, \& R. Mitkov (Eds.), Anaphora processing: Linguistics, cognitive and computational modelling, pages 283-300, Amsterdam: John Benjamins.

Grosz, J.B., \& Sidner, L. C. (1986). Attention, intention and the structure of discourse. Computational Linguistics, 12: 175-202.

Gundel, J. K., Hedberg, N., \& Zacharski, R. (1993). Cognitive status and the form of referring expressions in discourse. Language, 69(2): 274.

Halliday, M. A. K., \& Hasan, R. (1976). Cohesion in English. English Language Series, London: Longman.

Hinkel, E. (2001). Matters of cohesion in L2 Academic Texts. Applied Language Learning, 12(2): $111-32$.

Hopp, H. (2014). Working memory effects in the L2 processing of ambiguous relative clauses. Language Acquisition, 21(3): 250-278. DOI:10.1080/10489223.2014.892943

Ionin, T., Baek, S., Kim, E., Ko, H., \& Wexler, K. (2012). That's not so different from the: Definite and demonstrative descriptions in second language acquisition. Second Language Research, 28(1): 69-101. doi: 10.1177/0267658311432200

Jin, W. (2001). A quantitative study of cohesion in Chinese graduate students' writing: Variations across genres and proficiency levels. Retrieved from http://eric.ed.gov/?id=ED452726

Juvonen, P. (1996). Språkkontakt och språkförändring: Om användningen av demonstrativa pronomen i en sverigefinsk kontaktsituation. In L. Huss (Ed.), Många vägar till tvåspråkighet. Uppsala: Centre for Multi-Ethnic Research, Uppsala University.

Klin, C. M., Guzman, A. E., Weingartner, K. M., \& Ralano, A. S. (2006). When anaphora resolution fails: Partial encoding of anaphoric inferences. Journal of Memory and Language, 54: 131143.

Kornfilt, J. (1997). Turkish. London: Routledge.

Küntay, A., \& Özyürek, A. (2006). Learning to use demonstratives in conversation: What do language specific strategies in Turkish reveal? Journal of Child Language, 33: 303-320. doi: $10.1017 / \mathrm{S} 0305000906007380$

Lascarides, A., \& Asher, N. (2007). Frontiered discourse representation theory: Dynamic semantics with discourse structure. In H. Bunt \& R. Muskens (Eds.), Computing meaning, pages 87-124. Amsterdam: Springer. http://link.springer.com/chapter/10.1007/978-1-4020-5958-2_5

Levelt, W. J. (1993). Speaking: From intention to articulation (Vol. 1). MIT Press.

Levinson, S. C. (1983). Pragmatics. Cambridge University Press.

Linde, C. (1979). Focus of attention and the choice of pronouns in discourse. In Talmy (Ed.), Syntax and semantics 12: Discourse and syntax, pages 337-354, New York: Academic Press.

Lücking, A. (2018). Witness-loaded and witness-free demonstratives. Atypical demonstratives: Syntax, semantics and pragmatics, 568: 255.

Lyons, J. (1977). Semantics, Vol. 2. Cambridge: Cambridge University Press. 
McCarthy, M. (1994). It, this and that. In Coulthard, R.A. (Ed.), Advances in written text analysis, pages, 266-275, London: Routledge.

Niimura, T., \& Hayashi, B. (1996). Contrastive analysis of English and Japanese discourse anaphors from the perspective of L1 and L2 acquisition. Language Sciences, 18(3): 811-834. https://doi.org/10.1016/S0388-0001(96)00049-6

Nunberg, G. (1993). Indexicality and deixis. Linguistics and Philosophy, 16, 1-43.

O’Brien, E. J., Raney, G. E., Albrecht, J. E., \& Rayner, K. (1997). Antecedent retrieval processes. Journal of Experimental Psychology: Learning, Memory and Cognition, 16: 241-249.

Özyürek, A. (1998). An analysis of the basic meaning of Turkish demonstratives in face-to-face conversational interaction. In Santi S. et al. (Eds.). Oralite et gestualite: communication multimodale interaction, pages 604-614, Pars: L' Harmattan.

Öztürk, B. (2001). Turkish as a non-pro-drop language. In E. Erguvanl1-Taylan, (Ed.) The verb in Turkish, pages 239-259, Amsterdam; Philadelphia: John Benjamins.

Özil, Ş. \& Şenöz, C. (1996). Türkçe'de Bu, Şu Sözcükleri. X. Dilbilim Kurultayı Bildirileri, 27-39. İzmir: Ege Üniversitesi Basımevi.

Passonneau, R. J. (1993). Getting and keeping the center of attention. In M. Bates, \& R. M. Weischedel, (Eds). Challenges in Natural Language Processing. Cambridge: Cambridge University Press.

Peeters, D., \& Krahmer, E., Maes, A. (2020). A conceptual Framework for the Study of Demonstrative. https://doi.org/10.31234/osf.io/ntydq

Polanyi, L. (1986). The linguistic discourse model: Towards a formal theory of discourse structure. TR-6409. Cambridge MA: Laboratories Inc.

R Core Team (2020). R: A language and environment for statistical computing. R Foundation for Statistical Computing, Vienna, Austria. https://www.R-project.org/.

Roberts, L., Gullberg, M., \& Indefrey, P. (2008). On-line pronoun resolution in L2 discourse: L1 influence and general learner effects. Studies in Second Language Acquisition, 30: 333-357.

Sağın-Şimşek, Ç., Rehbein, J., \& Babur, E. (2009). İşlevsel Edimbilim Yöntemiyle Metin İçinde Gösterme Alanının İncelenmesi. Dilbilim Araştırmaları.

Sorace, A. (2011). Pinning down the concept of "interface" in bilingualism. Linguistic Approaches to Bilingualism, 1: 1-33. doi: 10.1075/lab.1.1.01 sor

Turan, Ü. D. (1997). Metin İşaret Adılları: BU, ŞU ve Metin Yapısı. XI. Dilbilim Kurultayı Bildirileri, 201-212. Ankara, Ortadoğu Teknik Üniversitesi.

Underhill, R. (2001). Turkish Grammar. Cambridge: The MIT Press.

Webber, B. (1989). Deictic reference and discourse structure. Technical Reports (CIS). Retrieved from http://repository.upenn.edu/cis_reports/848

Webber, B. L. (1991). Structure and ostension in the interpretation of discourse anaphors. Language and Cognitive Processes, 6(2): 107-35.

Wilson, F., Keller, F., \& Sorace, A. (2009). The antecedent preferences of anaphoric demonstratives and personal pronouns in L2 German. In J. Chandlee, M. Franchini, S. Lord, G-M. Rheiner (Eds.), Proceedings of the Boston University Conference on Language Development 33, pages 634-645, Somerville, MA: Cascadilla Press.

Zwaan, R. A. (1996). Processing narrative time shifts. Journal of Experimental Psychology: Learning, Memory, and Cognition, 22(5): 1196-1207. https://doi.org/10.1037/02787393.22.5.1196 